\title{
REVIEW OF INVESTIGATIONS PERFORMED IN THE U.S.S.R. ON CLOSE APPROACHES OF COMETS TO JUPITER AND THE EVOLUTION OF COMETARY ORBITS
}

\author{
E. I. Kazimirchak-Polonskaya
}

\section{INTRODUCTION}

The problem of the cosmogony of the solar system has long occupied a central position in astronomical research. The origin of comets plays a substantial role in the solution to this problem. It is therefore necessary to study in detail the "original" and "future" orbits of the comets with nearly parabolic orbits and to examine in particular the great orbical changes that take place when comets pass within the spheres of action of the giant planets.

In the U S.S.R. -- especially at the Institute for Theoretical Astronomy (I.T.A.) in Leningrad -- considerable attention is paid to investigations of this type. In this respect it is useful to refer to IAU Symposium No. 45, organized in Leningrad in 1970, and in particular to the introductory report by Chebotarev (1972)

\section{CALCULATION OF DEFINITIVE, ORIGINAL AND FUTURE ORBITS OF NEARLY PARABOLIC COMETS}

Early work in this field was carried out by Mikhajlov (1924), Sakk and Kulikov (1951), Dirikis (1953, 1954), Galibina (1953), and Shmakova (1953)

Makover (1955a) developed a special method for calculating the original and future orbits of long-period comets; the method involves taking the true anomaly, rather than the time, as the independent variabla. Several definitive, original and future orbits have been determined (Dirikis 1956; Barteneva I955. 1965, 1970, 1971,; Galibina 1953, 1963, 1964; Galibina and Barteneva 1965;

Belous 1960, 1964, 196́6, 1970) Galibina (1964) established that although the 
overwhelming majority of the original orbits were elliptical, about one half of the comets with definitive hyperbolic orbits continue to have hyperbolic orbits in the future and will therefore leave the solar system. Very similar results were obtained by Brady (1965). Reference should also be made to Sekanina's (1966) general catalogue of definitive, original and future orbits.

\section{EARLY SOVIET INVESTIGATIONS OF THE GREAT TRANSFORMATIONS OF COMETARY ORBITS IN JUPITER'S SPHERE OF ACTION}

The first work in the U.S.S.R. involving the investigation of large perturbations on cometary orbits and the successful prediction of the returns of short-period comets was carried out by Dubyago and Lexin (1923) and by Dubyago (1924, 1925).

Dubyago (1932a, 1932b, 1936, 1946, 1950,1956a, 1956b) constructed a numerical theory for the motion of P/Brooks 2 from before the comet's discovery in 1889 to 1960, taking into account the perturbations by the planets Venus to Saturn and a variable secular acceleration. He also studied two passages of the comet through Jupiter's sphere of action, to minimum distances of $\Delta_{\text {min }}=0.000964 \mathrm{AU}$ from Jupiter in 1886 and $\Delta_{\min }=0.086 \mathrm{AU}$ in 1922. In studying the first approach, he took into account the perturbations due to the Galilean satellites (although the effect proved to be negligible) and to Jupiter's oblateness. He also considered and dismissed the question, first raised by Poor (1894), of the possible collision of P/Brooks 2 with Jupiter's satellite $V$ as the reason for the comet's disruption.

Subsequently, Dubyago (1955a, 1955b, 1956c) was engaged in researci on the motion of p/Shajn-Schaldach and the great transformation of its orbit that took place during a close approach to Jupiter shortly before the comet's 
discovery in 1949. He also conducted theoretical investigations into the structure of comets and their possible disruption under the influence of Jupiter's destructive forces (Dubyago 1942) and into the nongravitational forces that affect the motions of comets (Dubyago 1948) Some of his ideas on the structure of the cometary nucleus are closely related to those of Whipple (1950, 1951); Dubyago (1948, 1956a) ccnsidered the dependence of the nongravitational forces on solar activity, on the perihelion distance of the comet and on the orientation of the comet's orbit.

An early work by the present author (Kazimirchak-Polonskaya 1950) included (1) a history of the studies of the motions of 32 short-period comets that approached Jupiter and other major planets; (2) a description of methods for considering the nongravitational effects on the motions of comets and a survey of the various hypotheses made between 1830 and 1950 on the causes of these effects; (3) the suggestion of a series of studies that might be made of orbital transformations for comets passing through and near Jupiter's sphere of action; and (4) the description of a new jovicentric method using special rectangular coordinates and taking into account the perturbations by the sun and planets, and the application of this method to a study of the motion of P/Wolf within Jupiter's sphere of action in 1922 ( $\Delta_{\min }=0.125 \mathrm{AU}$ ). The comparison of these calculations on $\mathrm{P} /$ Wolf with the observations in 1925 , as well as with the calculations (using a heliocentric method of variation of arbitrary constants) by Kamieński and Bielicki (1935), was very favourable

Sochilina (1958) studied the changes in the orbit of P/du Toit-NeujminDelporte when that comer passed near Jupiter's sphere of action in 195't $\left(\Delta_{\text {min }}=0.656 \mathrm{AU}\right)$ and noted that the mean motions of the conet and Jupiter 
would then be very close to $2: 1$ commensurability; Fokin (1958) studied the extended passage of P/Oterma through Jupiter's sphere of action $\left(\Delta_{\min }=\right.$ $0.168 \mathrm{AU}$ ) during 1936-1938, and Merzlyakova (1958) investigated that of $\mathrm{P} /$ Ashbrook-Jackson $\left(\Delta_{\mathrm{min}}=0.178 \mathrm{AU}\right)$ in 1945 .

A re-examination by Kastel' (1965) of the very close approach of $\mathrm{P} /$ Brooks 2 to Jupiter in 1886 gave $\Delta_{\min }=0.000985 \mathrm{AU}$, closely confirming the earlier result by Dubyago (1950).

3. DIFFERENCES AND DIFFICULTIES IN METHODS USED FOR THE CALCULATION OF LARGE PERTURBATIONS BY JUPITER

A statement of the problem and a review of research on the close approaches of short-period comets to Jupiter during 1770 - 1960 were given by KazimirchakPolonskaya (1961a, 1961b). The approaches of 33 short-period comets were discussed, and differences and difficulties in the methods used by the various authors were analyzed. The possibility of using these approaches to determine a more accurate value for the mass of Jupiter was demonstrated; such a determination has recently been made in the case of $P /$ Wolf, for example (Kazimirchak-Polonskaya 1972a). A number of questions arise:

(1) What method -- variation of arbitrary constants, perturbations in rectangular coordinates, or whatever -- provides the most accurate results in calculations on the transformations of cometary orbits in the spheres of action of Jupiter and other planets? A number of investigators (e.g., Rasmusen 1935; Herget 1947; Dubyago 1956a; Marsden 1963, 1967; Marsden and Schubart 1965; Stumpff 1972; Klepczynski 1972) have applied Cowell's well-known method of perturbations in rectangular coordinates. On the other hand, Merton (1927), and especially 
the Polish astronomers (Kamieński 1925, 1926, 1948a, 1948b, 1951, 1957, 1959; Kamienski and Bielicki 1935, 1936; Kepiński 1958) have utilized the method of variation of elements, defending it as being the most accurate method for calculating passages through Jupiter's sphere of action.

(2). What kind of method -- heliocentric or jovicentric -- should be preferred for very deep penetrations of comets into Jupiter's sphere of action? This is a very cogent question, for there are often severe discrepancies between the results of heliocentric and jovicentric methods applied to the same calculation.

(3) What differential formulae should be used in order to allow -- without repeated integration -- for small additional perturbations, such as those by Jupiter's satellites or by nongravitational forces?

(4) What criterion should be used in choosing the step-size for the integration?

\section{THE CHOICE OF AN EXPERIMENTAL OBJECT FOR} CHECKING THE VARIOUS METHODS

In order to overcome some of the difficulties mentioned in the previous Section it is useful to select a special experimental object. P/Wolf is an appropriate choice for three reasons: (1) the numerical theory for the motion of this comet was very skillfully constructed by Kamienski (1959) for the two isolated intervals of time 1884 - 1918 and 1925 - 1959; (2) P/Wolf passed close enough to Jupiter in 1922 that the correctness of the calculations can be verified by examining the pre-1922 and post-1922 observations/ and (3) the nongravitational forces on $\mathrm{P} /$ Wolf are practically insignificant. 
The planetocentric method has been developed in special coordinates (Kazimirchak-Polonskaya 1962a). Taking P/Wolf as an example, the author demonstrated the practical equivalence of the method of variation of arbitrary constants and the method in special rectangular coordinates, both in difference and in quadrature forms. Question (1) of the previous Section was therefore answered.

Some advantages of the method in special coordinates, as opposed to Cowell's method, have been demonstrated (Kazimirchak-Polonskaya 1961c); the jovicentric form of the new method was worked out; and it has been demonstrated that the heliocentric and jovicentric methods give practically identical results in the case of $\mathrm{P} /$ Wolf. Table 74 of the cited paper contains the answer to Question (2).

Question (3) was solved by developing Encke's method in planetocentric form (Kazimirchak-Polonskaya 1962b) and by producing a series of differential formulae for taking into account various small perturbations. The procedure was applied to the calculation of the perturbations by Saturn on P/Wolf during the encounter with Jupiter in 1922.

As regards Question (4), the author has developed a new criterion that gives the integration step size as a function of the distance of the comet from sun and all perturbing planets.

5. CONSEQUENCES OF THE DEVELOPMENT OF ELECTRONIC COMPUTERS

The rapid growth of electronic computers has opened up many new areas of research on the motions of the minor bodies of the solar system (KazimirchaxPolonskaya 1967a, 1957b, 1972b, 1972c; Kazimirchak-Polonskaya et al. 1953, 1972: 
Eazimirchak-Polonskaya and Terent'eva 1973). Among these numerous problems we shall nention only tro: (1) the construction of numerical theories of notion covering the whole period of observations of each comet, with full al1uwance for planetary perturbations and the effects of nongravitational Eorces; and (2) the investigation of the evolution of cometary orbits over the 400-year interval 1660 - 2060 The problems are closely related, and in practice the second one will be solved in conjunction with the first in the form of successive approximations.

The remainder of this review will be concerned mainly with the second problem, which can be subdivided as follows: (a) studying the orbital evolution of short-period comets of two or more apparitions; (b) redetermining the orbits of the short-period comets of only one apparition and then investigating the orbital evolution by a special method; (c) classifying the various approaches to the major planets and establishing the principal characteristics of the evolution of cometary orbits; (d) studying the transformations of the orbits of fictitious comets passing within the spheres of action of Uranus and Neptune and examining the mechanism whereby comets may be captured by these planets; (e) elucidating of the role of the giant planets in the evolution of cometary orbits; (î) specifying the successive stages in the evolution of cometary orbits, with consideration given to the stellar perturbations and the diffusion theory for 1ong-period comets; and ( $g$ ) analyzing all hypotheses on the orifin or comets and developing the most probable hypothesis linking, as far as possible, all comers into a single complex. 


\section{INVESTIGATIONS ON THE EVOLUTION OF COMETARY ORBITS}

AND COMETARY CAPTURE

In an important series of papers, Everhart (1967, 1968, 1969, 1970, 1972a, 1972b, 1973) has applied and improved the statistical methods dating back to Newton (1878, 1893). Havnes (1972), using a simplified formulation, arrives at particular conclusions concerning the dominant influence of Jupiter on the evolution of cometary orbits. As a complement to these studies Kresák (1957, 1972a, 1972b, 1973) has made extensive investigations in which the Jacobi integral in the problem of three bodies is used for solving various cosmogonic questions, and somewhat similar approaches have been made by Vaghi (1973a, 1973b) and Lowrey (1973).

Marsden (1963, 1967, 1970) Marsden and Aksnes (1967), Stumpff (1972) and Klepczyncki (1972) have carried out exhaustive research on orbital transformations of different comets in Jupiter's sphere of action by Cowell's method, or more recently by using the numerical integration program of Schubart and Stumpff (1966).

The Soviet astronomers also invariably use numerical integration programs in their research. Full allowance is made for planetary perturbations, and the methods are continually being improved in order to make them suitable for more and more precise modelling of real cometary motion, even when comets penetrate very deeply into the spheres of action of the major planets.

\section{METHODS AND COMPUTER PROGRAMS AT I.T.A.}

The complex of computer programs at I.T.A. includes routines for numerical integration, reduction of observations, comparison of calculations 
with observations and improvement of orbits. At present there are in use three essentially different methods of integration and corresponding sets of programs for the BESM-4 computer; those by Belyaev (1972), Bokhan (1972) and Kazimirchak-Polonskaya (1967c, 1972b). They supplement and, if necessary, are used to check each other.

In the set of programs by Belyaev the integration is performed by Cowell's method in single precision. Perturbations by Venus to Pluto are considered, and the step size ranges from 40 days to some tens of minutes. The choice of the step size is made automatically according to the criterion by Kulikov (1960). Nongravitational effects are not taken into account.

In the Bokhan programs the method of variation of arbitrary constants by Herrick (1972) is used. Perturbations by Mercury to Pluto are included, and there is the possibility of allowing for nongravitational effects using the model by Makover (1955b). The integration step is selected according to the criterion by Kazimirchak-Polonskaya (1967c, Table XII). The programs by Bokhan are intended mainly for investigating the motions of objects with highly eccentric orbits, notably P/Encke and (1566) Icarus.

The programs by the present author are in double precision and take into account the perturbations by Mercury to Pluto and nongravitational effects. The choice of integration step ranges from 20 days to $5 / 64$ day ( 1 hour 52.5 minutes). The author's set of programs, which includes some of the standard programs by Bokhan $(1969,1972)$, is especially suited for modelling the great transformations of cometary orbits in the sphere of action of any major planet. 
8. THE USE OF METHODS AND SETS OF I.T.A. PROGRAMS

FOR CONSTRUCTING NUMERICAL THEORIES OF COMETARY MOTION

The Belyaev set of programs is the one that is in most widespread use, both at I.T.A. and at scientific centers in Kazan, Kiev, Tomsk and elsewhere. Among the comets investigated using these programs are P/Faye (Belyaev and Khanina 1972), P/Giacobini-Zinner (Evdokimov 1972), P/Tempel-Tuttle (Kondrat'eva 1972), P/Stephan-Oterma (Shmakova 1972) and P/Ashbrook-Jackson (Merzlyakova 1974). The programs have also been applied to studies of the orbital stability of minor planets with "cometary" eccentricies (Chebotarev et al. 1970, 1972, 1974) and of the orbital evolution of meteor streams.

Using her own programs, the present author (Kazimirchak-Polonskaya 1972b) has eliminated the 1918 - 1925 discontinuity in Kamieński's (1959) theory of P/Wolf. Belous $(1972,1974 \mathrm{a}, 1974 \mathrm{~b})$ applied these same programs to P/Borrelly and to linking the two apparitions of $\mathrm{P} /$ Westphal and P/Brorsen-Metcalf (Belous 1974c, 1974d). The two apparitions of P/Stephan-Oterma have been Iinked (Kazimirchak-Polonskaya and Belous 1974) Bokhan and Chernetenko (1974) have investigated the motion of $\mathrm{P} /$ Encke during 1901 - 1970, and Kazimirchak-Polonskaya and Terent'eva (1973) have investigated the motion and evolution of the orbits of various meteor streams.

\section{THE EVOLUTION OF COMETARY ORBITS DURING 1660-2060}

The orbital evolution during 1660-2060 has been studied for a total of 52 short-period comets (although in a few cases, when an orbit was not sufficiently reliable, the interval was reduced to only 200 years). The more 
interesting results have been included in the following series of papers: Belyaev (1966, 1967, 1973a, 1973b); Belyaev and Khanina (1972); Belyaev and Reznikov (1973); Belyaev and Stal'bovskij (1974); Belyaev and Shaporev (1974); Belous (1974b); Kazimirchak-Polonskaya (1966, 1967a, 1967d, 1967e, 1967f, 1971, 1972c, 1973). In the case of $\mathrm{P} /$ Wolf the effects of nongravitational forces were included too (Kazimirchak-Polonskaya 1967d), the comet's variable secular deceleration having been changed after each approach to Jupiter according to the law established by Kamieński (1961). Although there were two close approaches to Jupiter going back from the discovery date of 1884 to $1660\left(\Delta_{\min }=0.12\right.$ and $\left.0.25 \mathrm{AU}\right)$, comparison with a computer run in which the nongravitational forces were excluded shows that their influence was negligible

Belyaev (1973a) studied the orbital evolution of $P /$ Neujmin 2, first on the basis of the system of orbital elements by Neujmin (1948), and then starting from elements he had determined himself. In spite of the 14 close approaches to Jupiter during the 400-year interval, the two results are very similar

of course, one cannot generalize this finding to all comets: there are some rather exceptional comets (e.g., P/Lexell and P/Kearns-Kwee) where the smallest changes in the initial elements alter the whole course of the calculated orbital evolution quite dramatically other single-apparition comets whose orbital evolution has been studied are P/Schwassmann-Wachmann 3 (Belyaev and Shaporev 1974), P/Churyumov-Gerasimenko (Belyaev 1973b), and P/Gunn and P/Kojima (Belyzev and Reznikov 1973) 


\section{THE CLASSIFICATION OF THE APPROACHES OF SHORT-PERIOD}

COMETS TO THE MAJOR PLANETS

The study of the orbital evolution of 52 comets involved some 320 close approaches to Jupiter, more than 40 approaches to Saturn and a few approaches to Uranus. There were 86 passages through Jupiter's sphere of action and one passage through that of Sacurn. Close approaches of shortperiod comets to Jupiter and Saturn are certainly not infrequent events, and they follow a complex regularity the study of which is of interest from many points of view.

On the basis of the available literature, Kazimirchak-Polonskaya (1967b) has classified 157 approaches of 63 short-period comets to Jupiter in terms of $\Delta_{\min }$

\section{THE PRINCIPAL CHARACTERISTICS OF THE EVOLUTION OF} COMETARY ORBITS SUBJECTED TO GREAT PERTURBATIONS BY JUPITER

The typical transformations of cometary orbits that arise as the result of passages through or near Jupiter's sphere of action are illustrated in the following eight general examples:

(1). Comets that remain in Jupiter's family, but which are at first invisible from the earth, because their orbits have large perihelion distances and low eccentricities. After an approach to Jupiter, usually shortly before discovery, the perihelion distances are reduced, and the orbital eccentricities are increased. Examples are P/Churyumov-Gerasimenko (Fig. 1) and P/Gunn (Fig. 2)

(2). Comets that remain in Jupiter's family, but whose perihelion distances and orbital eccentricities pulsate in a generaily irregular manner 


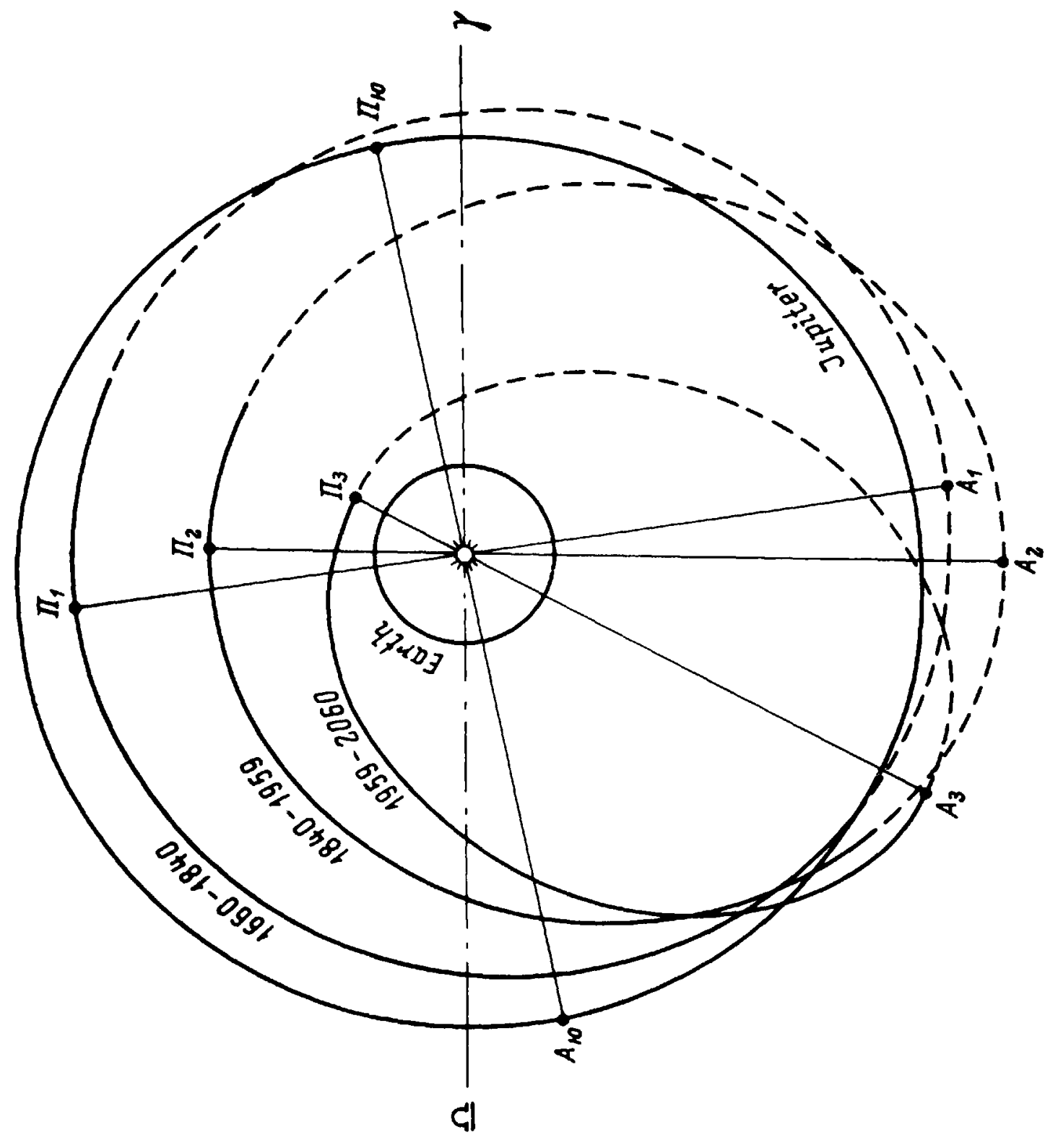

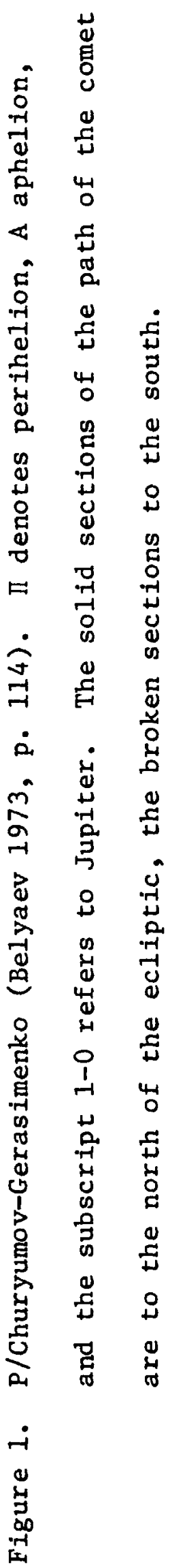




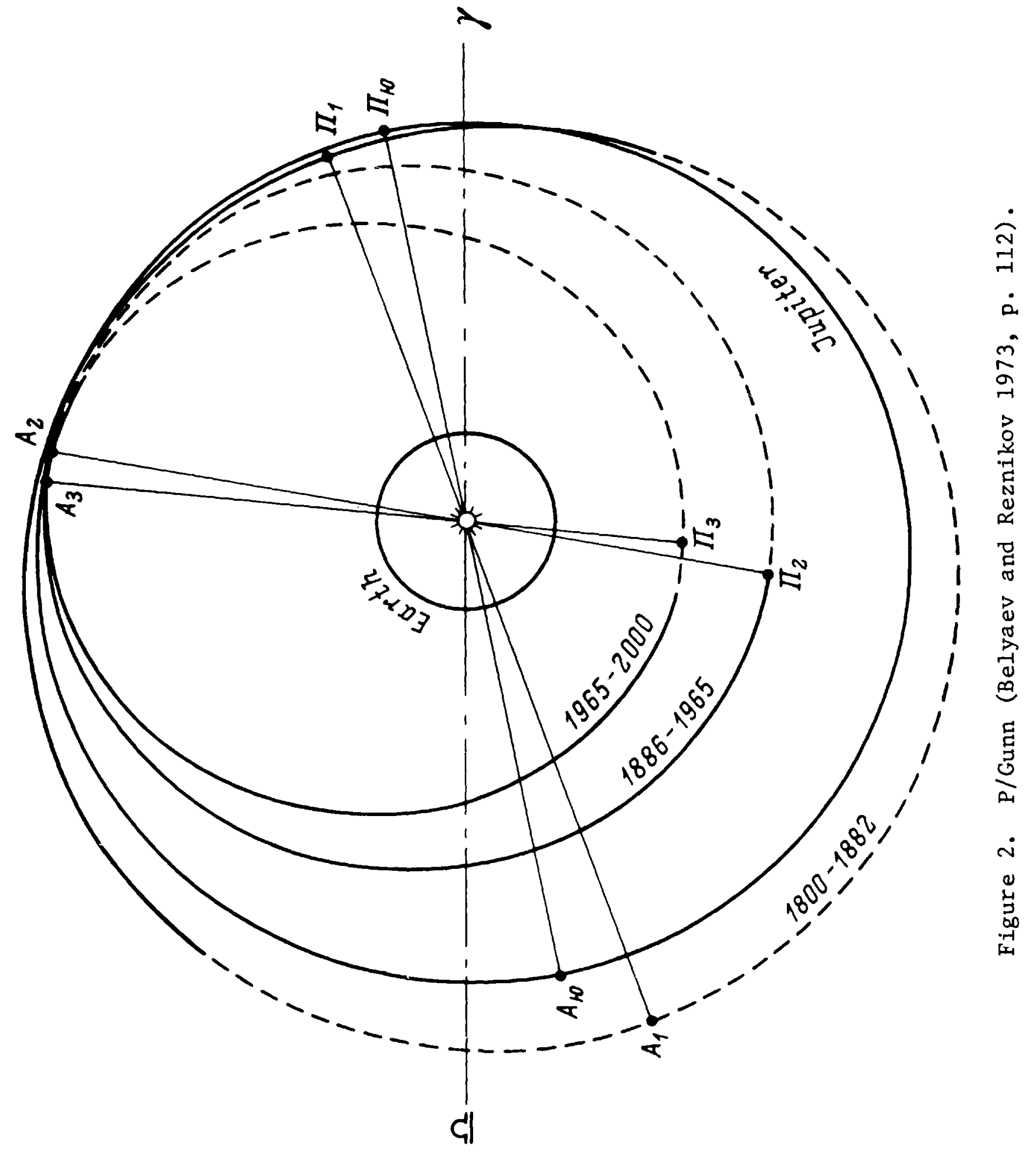


Examples are P/Wolf (Fig. 3), P/Wolf-Harrington (Fig. 4) and P/SchwassmannWachmann 2 (Fig. 5). This type of motion was first described by Kamienski (1954).

(3) Comets captured by Jupiter from Saturn's family * These comets initially had large perihelion distances, but successive approaches to Jupiter cause them to decrease until the comets could be discovered. In the course of time the perihelion distances may increase again, and the comets will become lost from view: Examples are P/Whipple (Fig. 6) and P/Comas Solá (Fig. 7):

(4). P/Oterma (Fig. 8) has an exceptionally unstable orbit. Jupiter captured it during 1936-1938 from Saturn's family into an orbit near 3:2 commensurability. After an interval of some 20 years another approach to Jupiter caused it to be ejected back into Saturn's family.

(5). In contrast to P/Oterma, there must be comets that have stable orbits for extensive intervals of time. They are usually not observed and are located in the regions between neighbouring planetary families (Jupiter and Saturn, Saturn and Uranus, and especially Uranus and Neptune), as well as beyond the orbit of Neptune. The one observable example of such a comet is P/Schwassmann-Wachmann 1 , which is located entirely between the orbits of Jupiter and Saturn.

(6) Coinets from the region between Saturn and Uranus initially having perihelia on the orbit of Jupiter and captured into the Jupiter family Examples are P/Brooks 2 (Fig. 9) and P/Schwassmann-Wachmann 3, for which $\Delta_{\min }=0.0056 \mathrm{AU}$ in 1882 (Fig. 10)

* We shall continue to define comet "families" on the basis of aphelion distance. However, it would be useful to consider at some time in the future the alternative definition proposed by Bielicki (1972). 


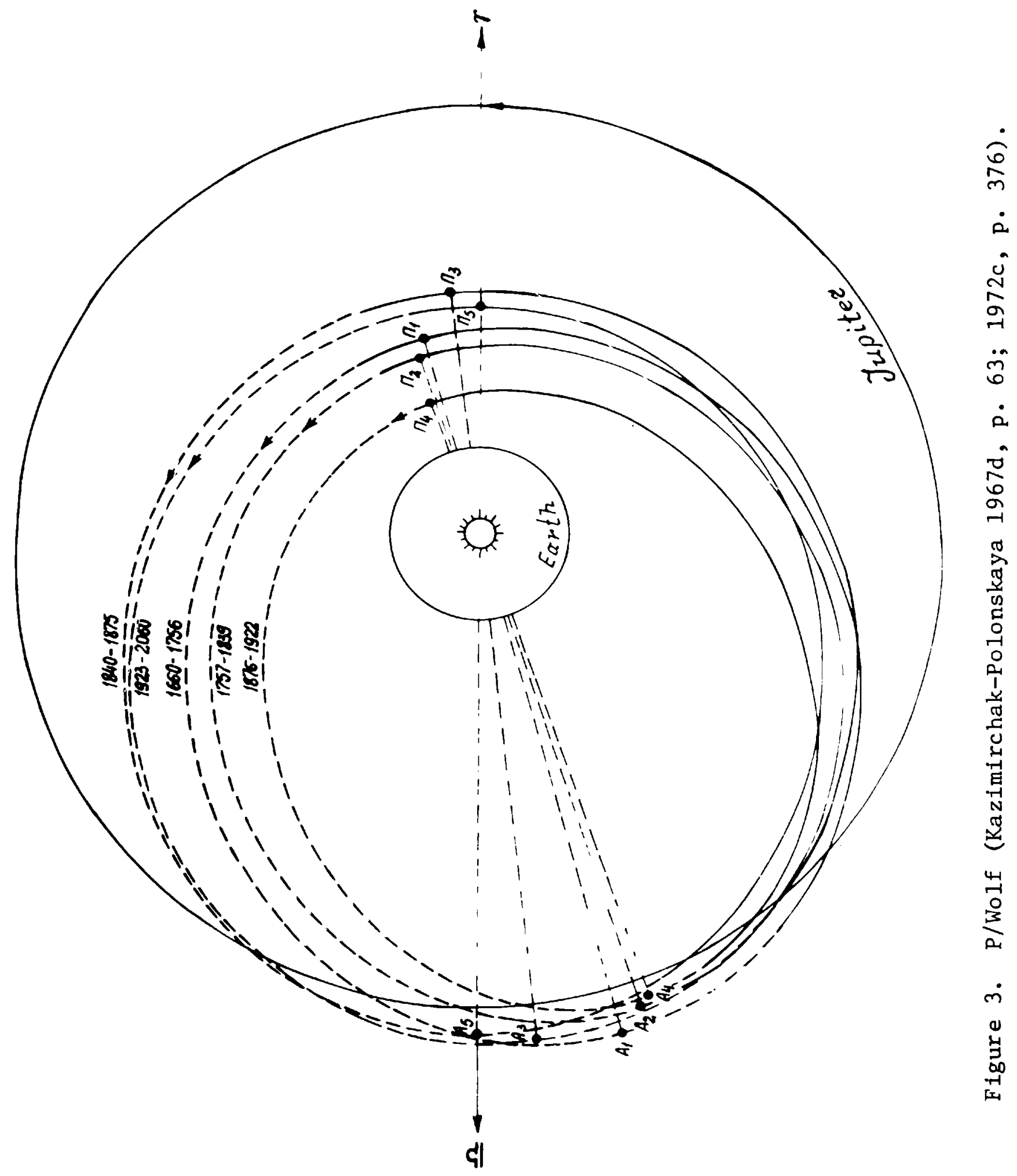




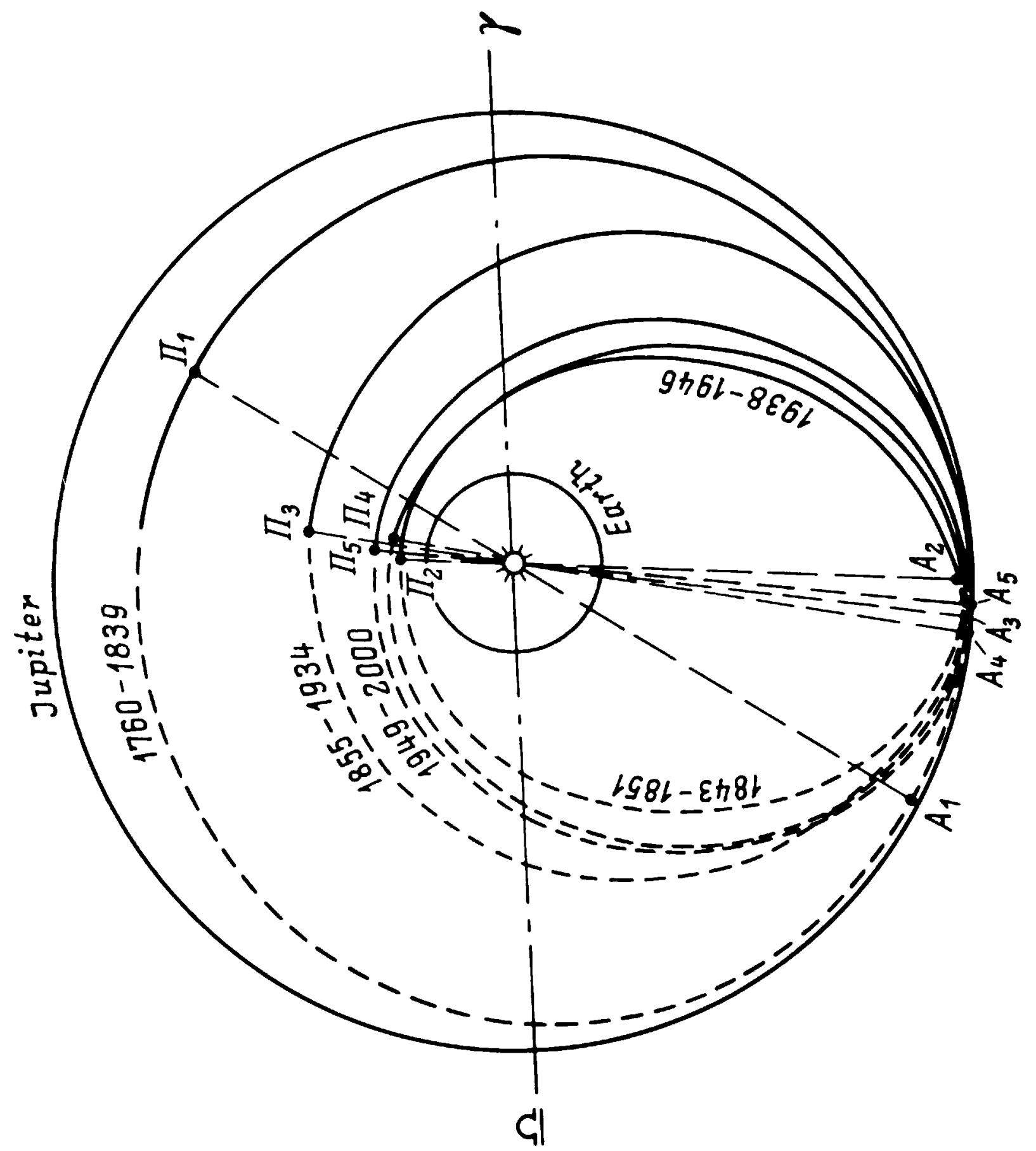

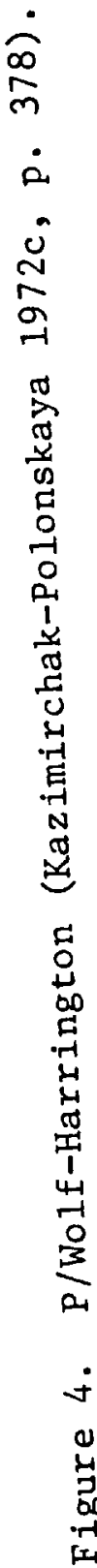




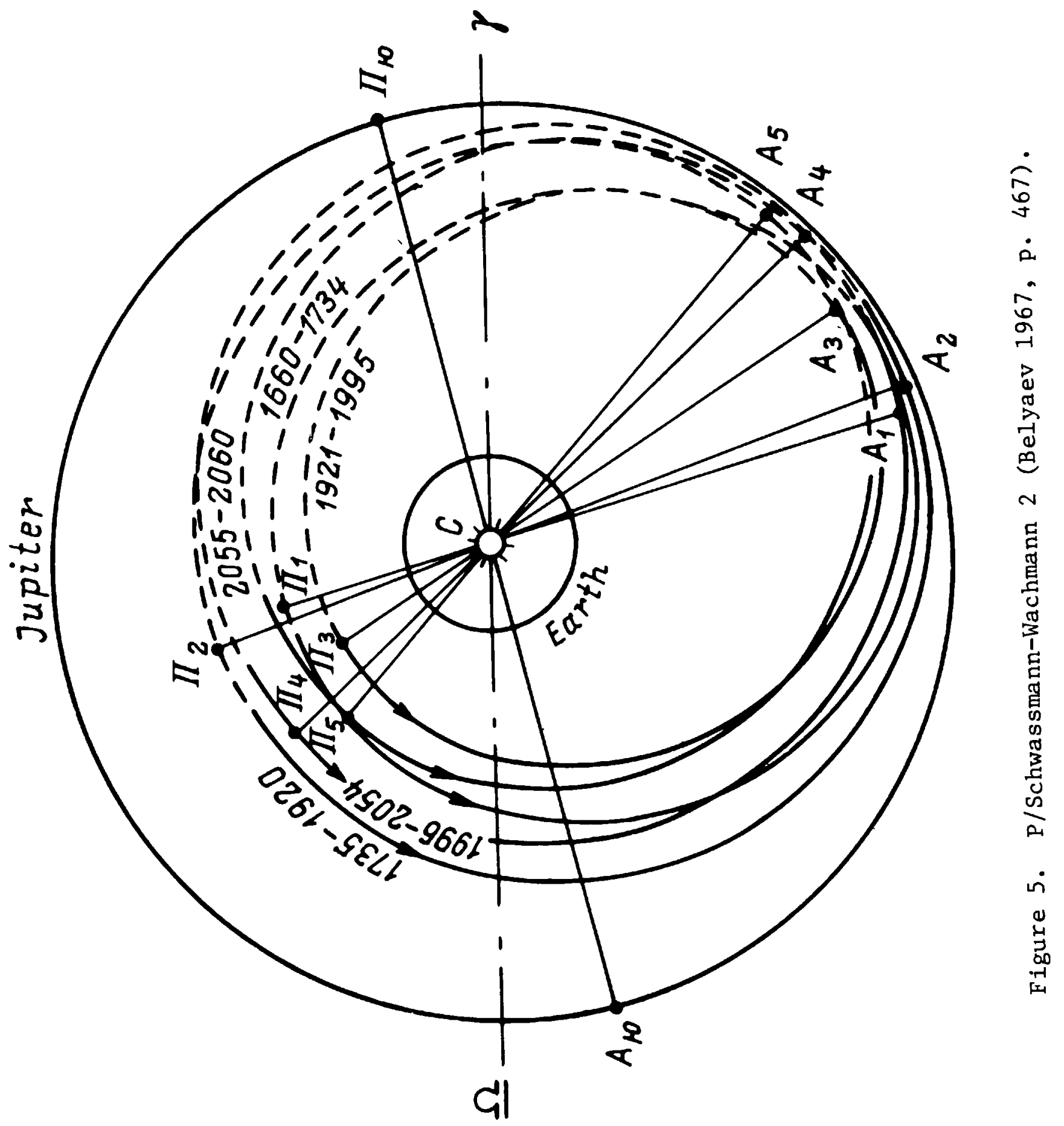




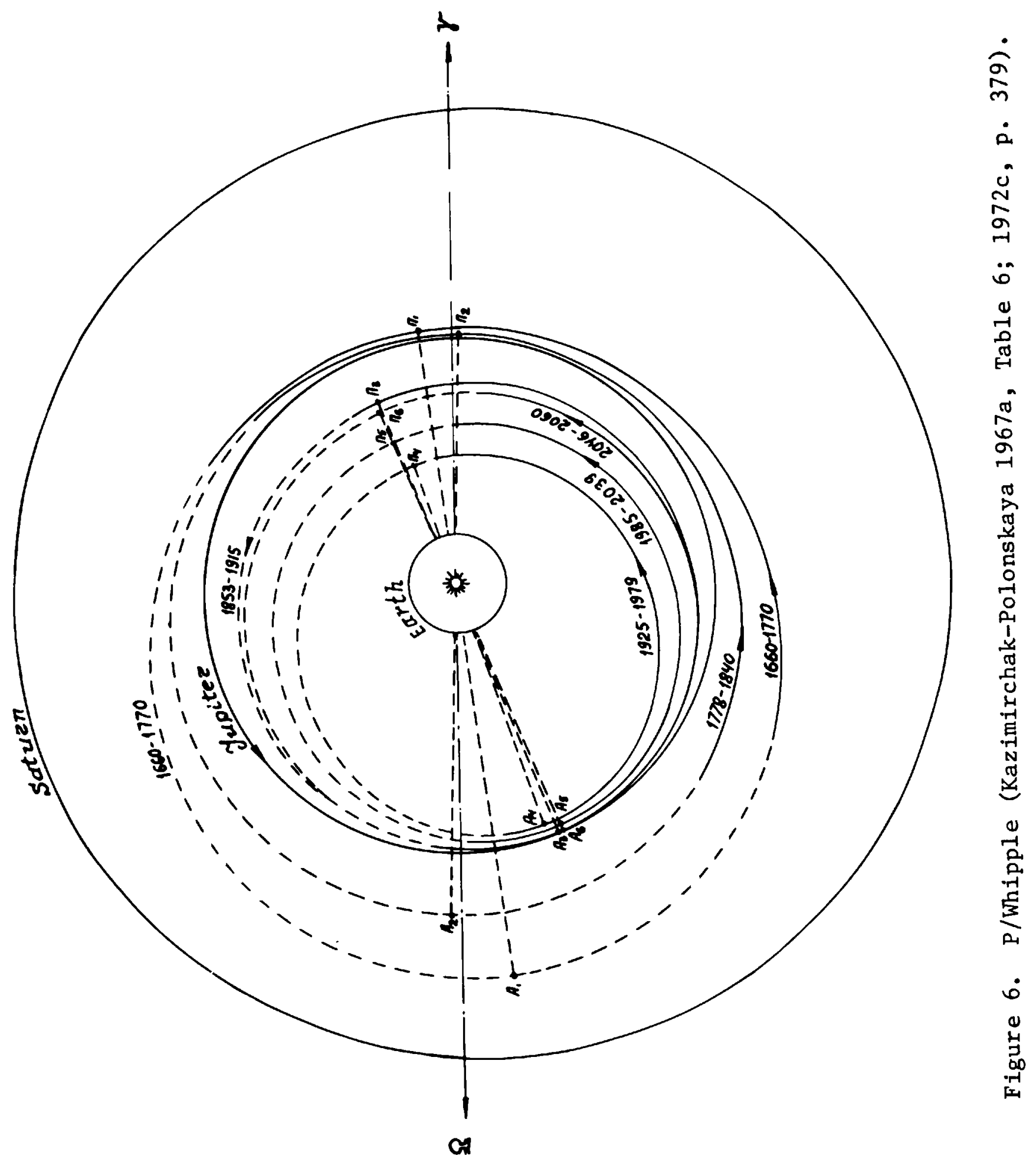




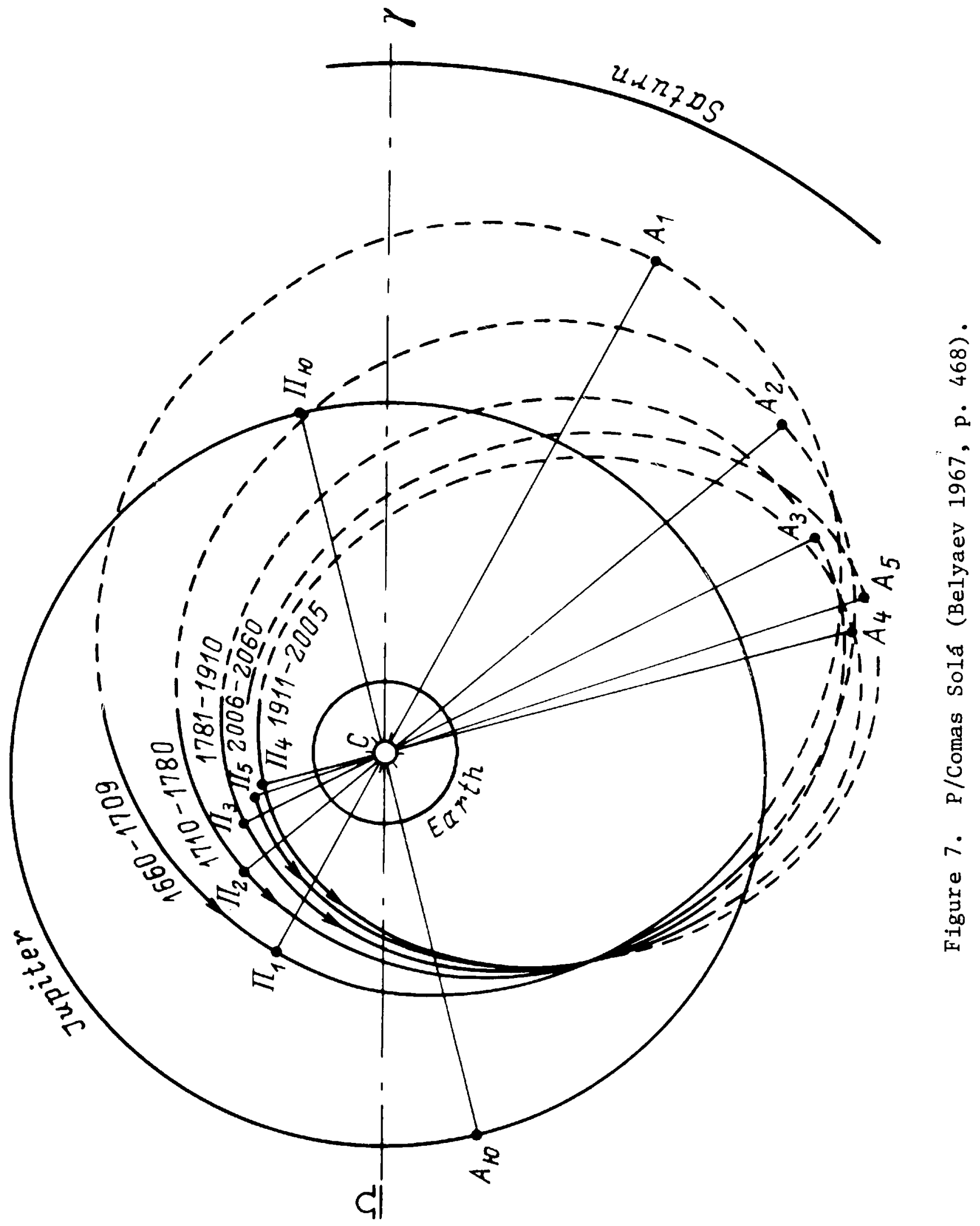




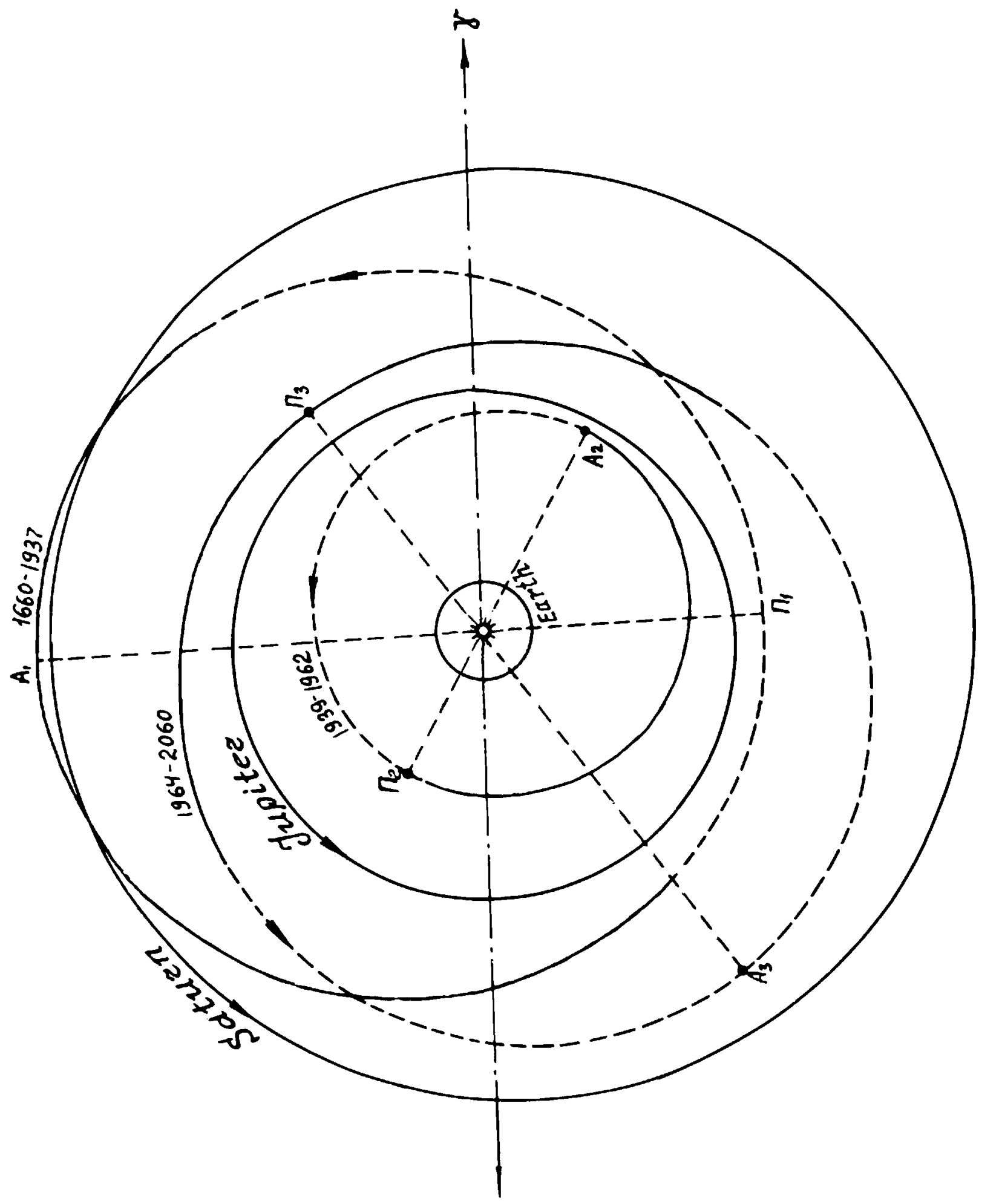

$\stackrel{\circ}{\circ}$

$\dot{n}$

i

ลั

$\ddot{G}$

م)

กั

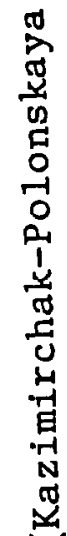

م.

$\infty$

崩

al 


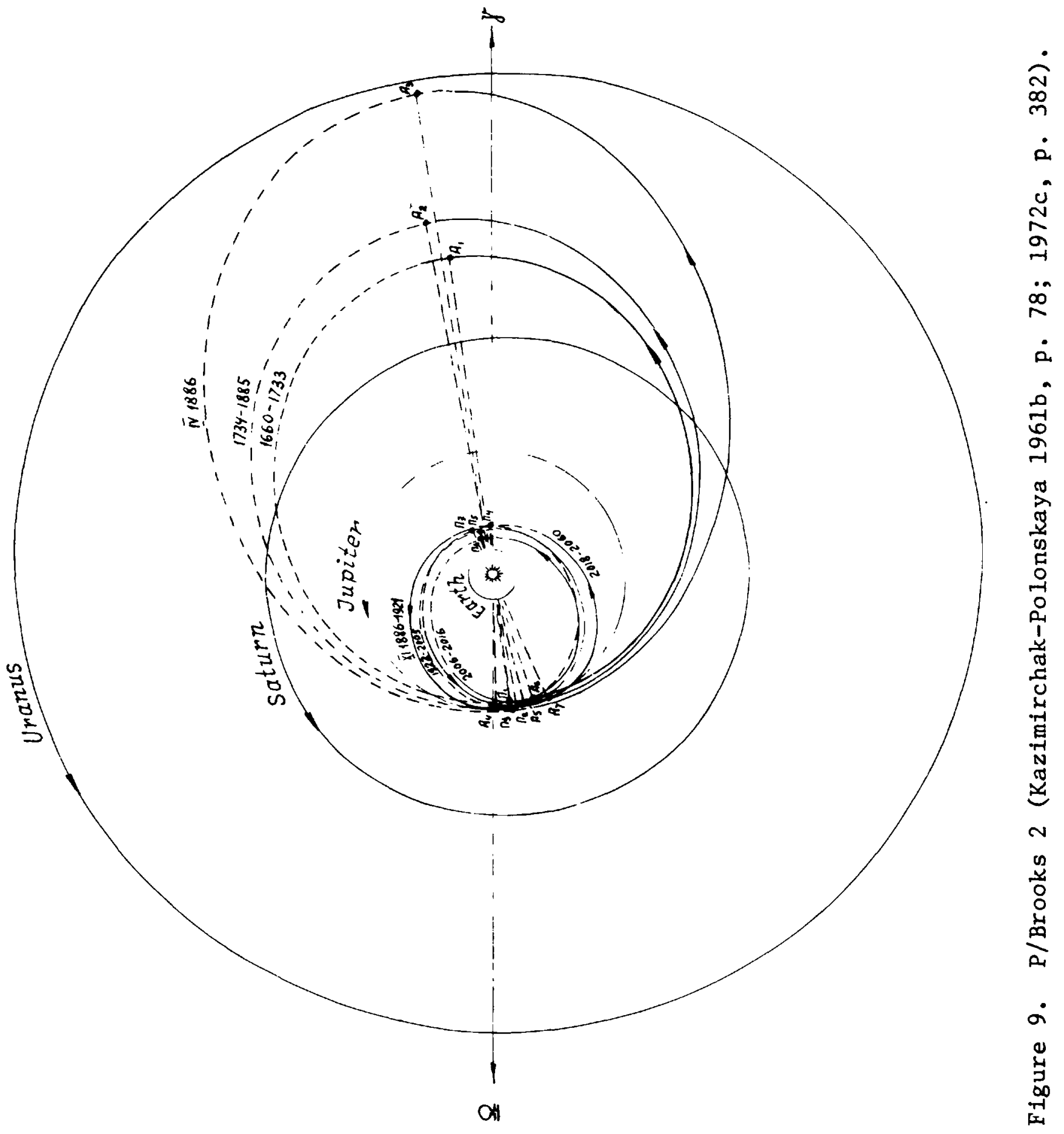




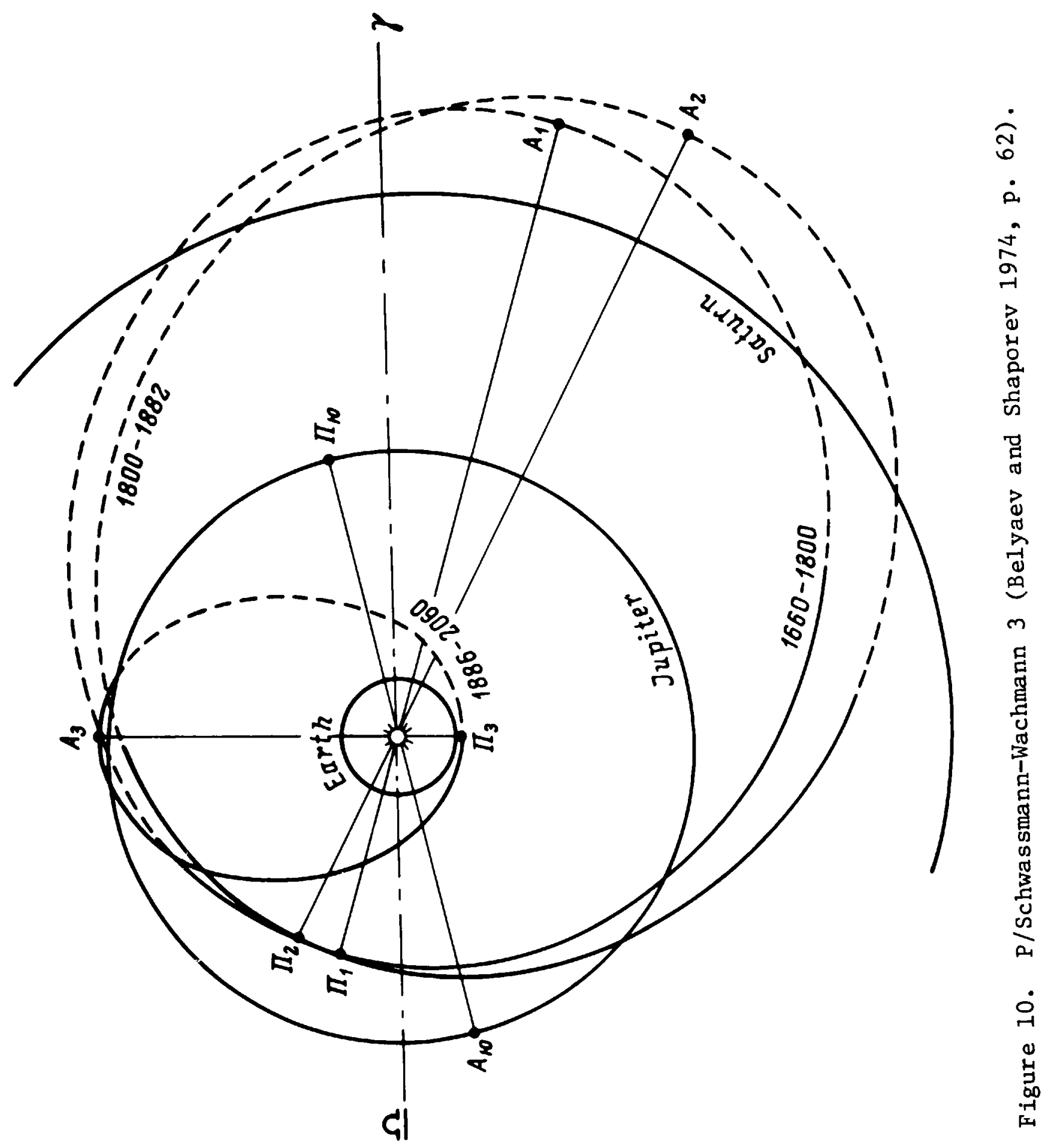


(7) $\mathrm{P} /$ Lexel1 (Fig. 11) was captured by Jupiter in $1767\left(\Delta_{\mathrm{min}}=0.018 \mathrm{AU}\right)$ from a nearly circular orbit (perihelion distance $q=3.3 \mathrm{AU}$, period $\mathrm{P}=10$ years) into an elongated elliptical orbit with its perihelion inside the orbit of Venus $(q=0.67 \mathrm{AU}, \mathrm{P}=5.6$ years). The comet was discovered in 1770 as a bright object, owing to its exceptionally close approach to the earth (within $0.016 \mathrm{AU})$. The comet encountered Jupiter again in 1779 , and this time the approach was so close $\left(\Delta_{\min }=0.0015 \mathrm{AU}\right)$ that the comet was ejected on an orbit having its aphelion far beyond the orbit of P1uto. The period of revolution increased to 260 years, and since the perihelion was removed to the arbit of Jupiter the comet will no longer be accessible to observation. As already noted, the future evolution of this comet is very sensitive to the initial conditions, and Fig. 12 shows the effect of changing the 1770 orbit slightly It is not impossible that $\mathrm{P} /$ Lexell left the solar system on a strongly hyperbolic orbit.

(8). The orbital evolution of P/Kearns-Kwee (Fig. 13) was investigated by us on the basis of the provisional elements determined by Marsden (1964) from observations covering an interval of six months. It illustrates the possible two-stage capture of the comet by Jupiter: during the first very close approach $\left(\Delta_{\text {min }}=0.042 \mathrm{AU}\right)$ in 1855 Jupiter captured the comet from a hyperbolic orbit* into the Neptune family. After two revolutions around the sun, the comet passed deeply into Jupiter's sphere of action in $1961\left(\Delta_{\min }=\right.$ $0.032 \mathrm{AU})$ and was discovered two years later as a short-period comet of Jupiter's family.

* It is necessary to stress that this is only a possible evolution and probably a mathematical fiction. A calculation by Marsden and Aksnes (1967), considering observations over an 18-month arc, indicates that the 1855 approach to Jupiter did not really occur 


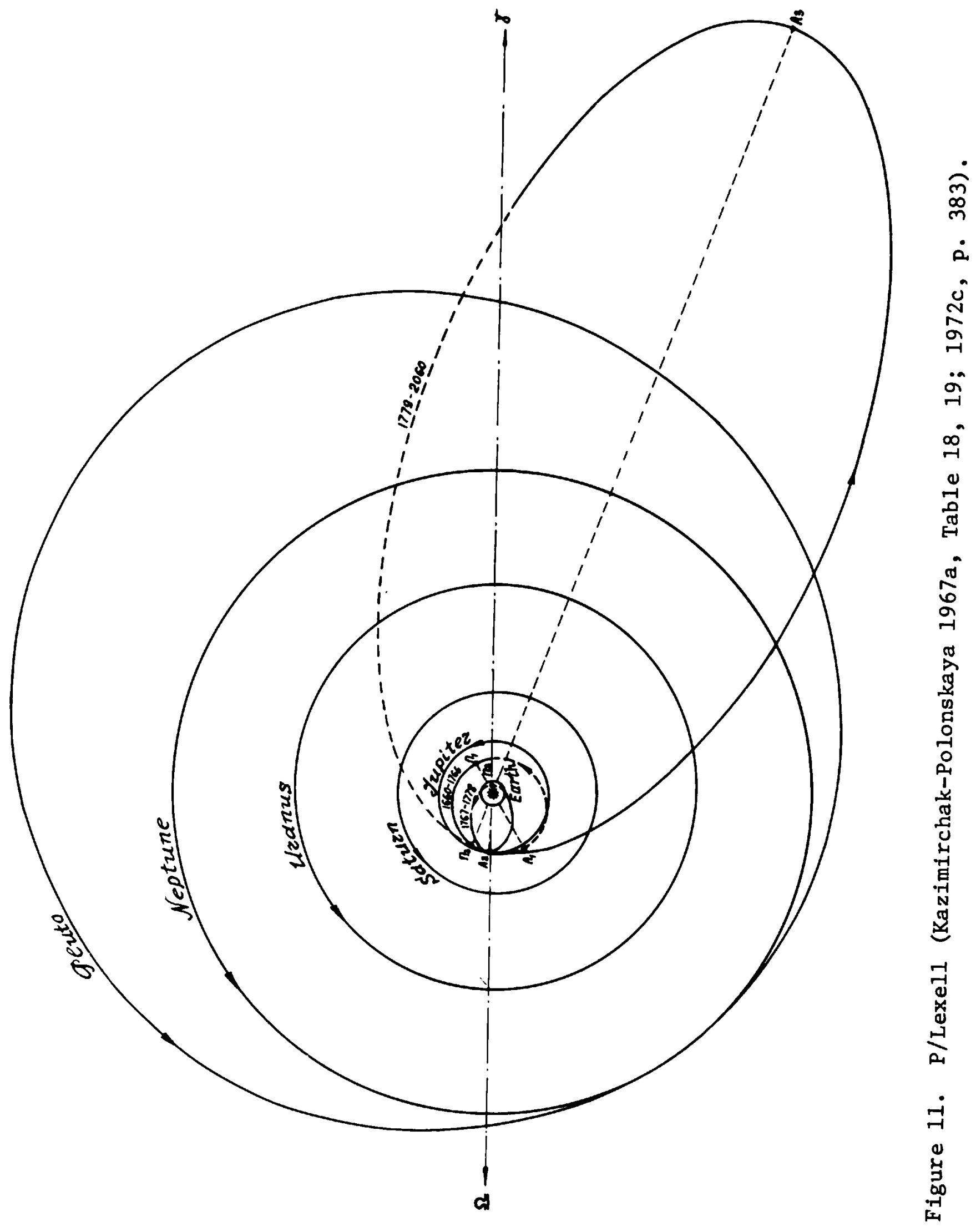




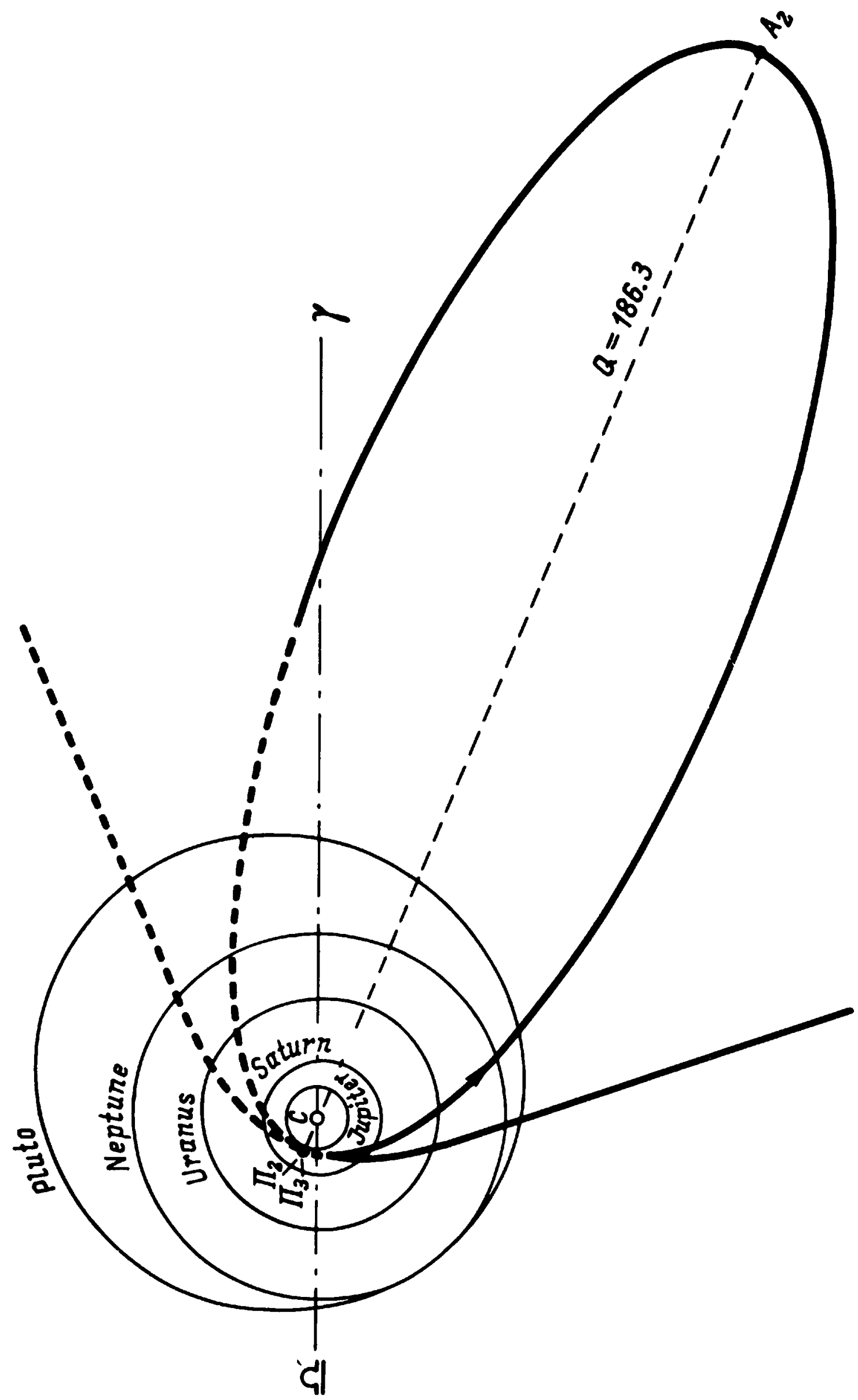

童 


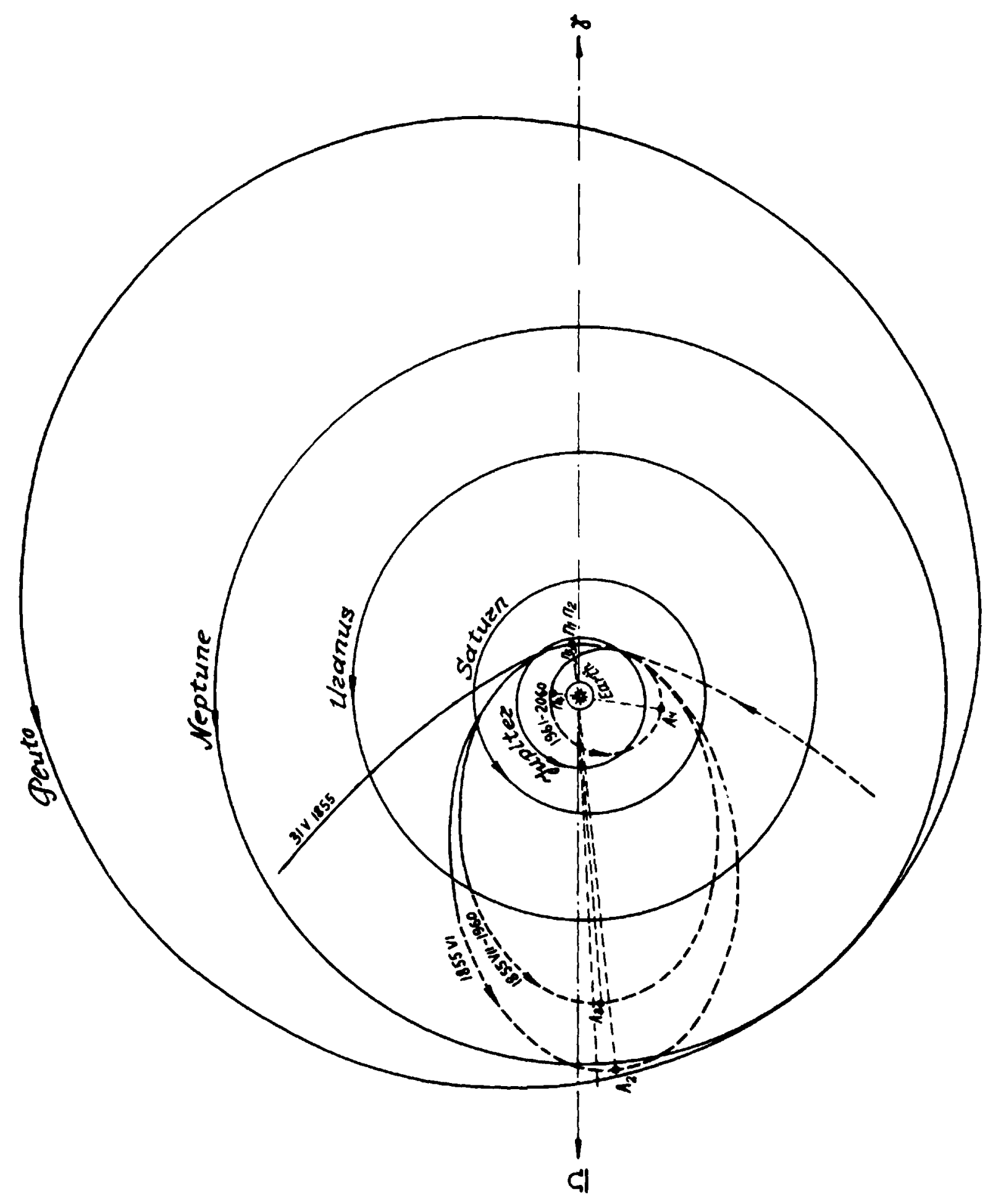

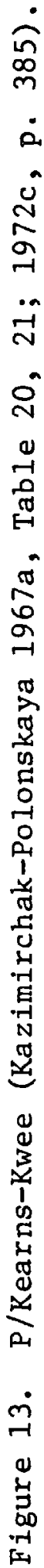




\section{GREAT PERTURBATIONS OF COMETARY ORBITS BY SATURN}

We have also studied the orbital evolution of some of the short-period comets belonging to Saturn's family, notably P/Neujmin 1, P/Neujmin 3 and P/Gale. In the course of a 200-year interval P/Neujmin 3, for instance, experienced six approaches to Saturn, and four of them had quite considerable effects, causing perturbations of more than $10^{\circ}$ in $\omega$ and in $\Omega$. After a very close approach of this comet to Jupiter in $1850\left(\Delta_{\min }=0.12 \mathrm{AU}\right)$ Saturn ceased to be the dominant influence on its evolution. During $1660-2060 \mathrm{P} / \mathrm{Neujmin} 1$ makes six approaches to Saturn and none to Jupiter, which shows that the secular evolution of the orbit of this comet is essentially determined by Saturn. Perhaps the most interesting comet of Saturn's family is P/Gale. According to the initial system of elements obtained by Dinwoodie (1959) from the two apparitions, between 1660 and $2060 \mathrm{P} /$ Gale made nine approaches to Jupiter and eight to Saturn. One of the latter approaches is the only known passage of a comet through Saturn's sphere of action ( $\Delta_{\min }=0.17 \mathrm{AU}$ in 1798 ). As is happened, this approach did not result in a particularly great transformation of the orbit of P/Gale. By varying Dinwoodie's elements slightly, we were able to decrease $\Delta_{\min }$ in 1798 to only $0.095 \mathrm{AU}$, and this caused a change of $173^{\circ}$ in $\Omega$.

It thus appears that although Jupiter must play the dominant role in the evolution of cometary orbits, Saturn can exert a strong temporary influence on the evolution of the orbits of some of the comets belonging to its family

13. GREAT ORBITAI TRANSFORMATIONS OF FICTITIOUS CONETS

IN THE SPHERES OF ACTION OF URANUS AND NEPTUNE

Although we have investigated the orbital evolution of several of the 
conets belonging to the families of Uranus and Neptune, (e.g., P/StephanOterma, P/Pons-Brooks, P/Brorsen-Metcalf and P/Nestphal), there were only two minor approaches of $P /$ Stephan-Oterma to Uranus, and none of the comets made any close approaches to Uranus or Neptune. In order to study the effects of such close encounters it was necessary to produce some fictitious comets. In order that these comets might bear some resemblance to real comets it is essential to discuss the existence of the Oort cometary cloud and the theory of diffusion and to consider the distribution of some of the orbital elements of long-period comets.

Although the existence of the Oort cloud cannot be checked directly, some indication of its possible dimensions and structure may be determined by studying the "original" orbits of long-period comets for which fairly reliable definitive orbits have been calculated. The theory of diffusion, which dates back to van Woerkom (1948), has been elaborated by Oort (1950), Lyttleton (1953), Shtejns (1960, 1961, 1952, 1964, 1972), Shtejns and Kronkalne (1964, 1968), Shtejns and Riekstyn'sh (1960), Shtejns and Sture (1962), Kendall (1961) and Whipple (1962). We know that comets that formerly belonged to the cometary cloud gradually diffuse into the inner part of the solar system. Consequently, there must be a concentration of invisible comets having low-eccentricity, low-inclination orbits and perihelia far from the earth. Many of them could be around the orbit of Neptune.

The distribution of semimajor axes and perihelia of the orbits of longperiod comets has been studied by many astronomers, notably Svedstrup (1883), Oppenheim (1924), Witkowski (1953, 1965, 1968, 1971, 1972) and Hurnik (1959, 1964) They arrived at the conclusion that there exists an incontestable connection between the distribution of the perihelia of these comets and the galactic equator, which fact testifies to the interstellar origin of comets. 
Lyttleton (1948, 1953) suggested that the passage of the sun through a uniform interstellar dust cloud could lead to the formation of comets by accretion.

In view of the above, we have considered in our studies comets having initial orbits of two types:

(1) Comets with nearly circular, low-inclination orbits that formerly belonged to the cometary cloud on the periphery of the solar system, but which have already approached the orbit of Neptune as the result of diffusion. These may also be the comets which belonged, according to a hypothesis by Whipple (1972) to an extensive belt of comets beyond Neptune's orbit.

(2). Comets of cosmic origin arriving directly from interstellar space on hyperbolic orbits. These orbits are both direct and retrograde and penetrate Neptune's sphere of action.

We shall designate the fictitious comets passing through the sphere of action of Uranus by $U-1$ and $U-2$ and those penetrating the sphere of action of Neptune by $\mathrm{N}-1, \mathrm{~N}-2, \ldots, \mathrm{N}-8$. In an earlier paper (Kazimirchak-Polonskaya 1972c) we have treated the characteristic features of the orbital evolution of the fictitious comets $\mathrm{U}-1, \mathrm{U}-2, \mathrm{~N}-1, \mathrm{~N}-2$ and $\mathrm{N}-3$.

\section{ORBITAL EVOLUTION OF COMETS $\mathrm{N}-4$ TO $\mathrm{N}-8$}

Comet $\mathrm{N}-5$ has a nearly circular transplutonian orbit of small inclination $\left(i=8^{\circ} .7\right)$; its perihelion is located near the orbit of Neptune, and its revolution period is 210 years. Having penetrated deeply into Neptune's sphere of action in 1715, ( $\left.\Delta_{\min }=0.0004 \mathrm{AU}\right)$, this comet leaves along a direct orbit $\left(i=22^{\circ} .1\right)$ having its perihelion between the orbits of Uranus and Satum, its aphelion not far beyond the orbit of Neptune and a revolution period of 103 years (Fig. 14) 


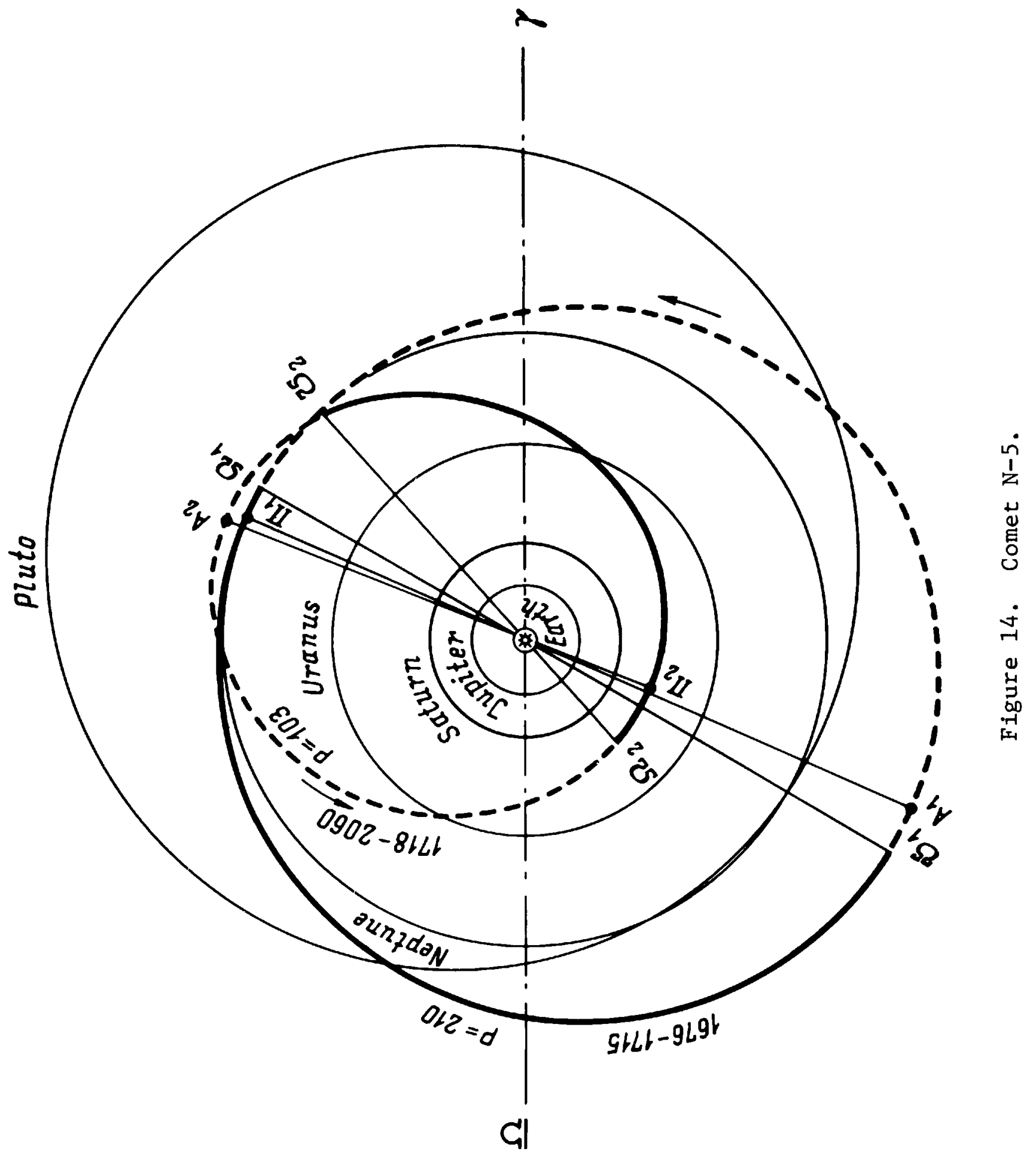


Comet $\mathrm{N}-6$ is of interstellar type; it has a retrograde hyperbolic orbit $\left(i=135^{\circ} .2\right)$, and its perihelion is located between the orbits of Neptune and Uranus. Its encounter with Neptune occurs in $1710\left(\Delta_{\min }=0.0005 \mathrm{AU}\right)$, before perihelion passage. The comet is ejected along a nearly circular, direct, transplutonian orbit $(1=16: 0)$ having its perihelion near the orbit of Neptune, its aphelion beyond the orbit of Pluto, and a revolution period of 220 years (Fig. 15).

Comet $\mathrm{N}-7$ is another retrograde interstellar comet $\left(i=159^{\circ} .0\right)$, but its perihelion is located between the orbits of Uranus and Saturn. It encounters Neptune after perihelion, passes twice within a very small distance of the planet $\left(\Delta_{\text {min }}=0.00035\right.$ and $\left.0.00065 \mathrm{AU}\right)$. Afterwards it retains its retrograde orbit $\left(i=136^{\circ} .6\right)$, but with a perihelion distance of only $1.2 \mathrm{AU}$; its aphelion is locazed near Neptune's orbit, and the revolution period is 61 years (Fig. 16). The final orbital inclination of comet $\mathrm{N}-7$ is very similar to that of $\mathrm{P} /$ PonsGambart, while the size and shape of its orbit are practically identical with those of P/Westphal.

Comet $\mathrm{N}-8$ also has a hyperbolic retrograde orbit, but after penetrating Neptune's sphere of action, it leaves on an orbit that is even more hyperbolic than initially.

Finally, we briefly mention Comet $\mathrm{N}-4$, discussed in detail elsewhere (Kazimirchak-Polonskaya 1975). It is captured as a stable satellite of Neptune having an orbit internediate between those of Triton and Nereid (Fig. 17). We conclude that the planets Jupiter to Neptune, with their great masses and extensive spheres of action, have a substantial effect on the evolution of the orbits of comets These planets can transfer comets from one planetary 


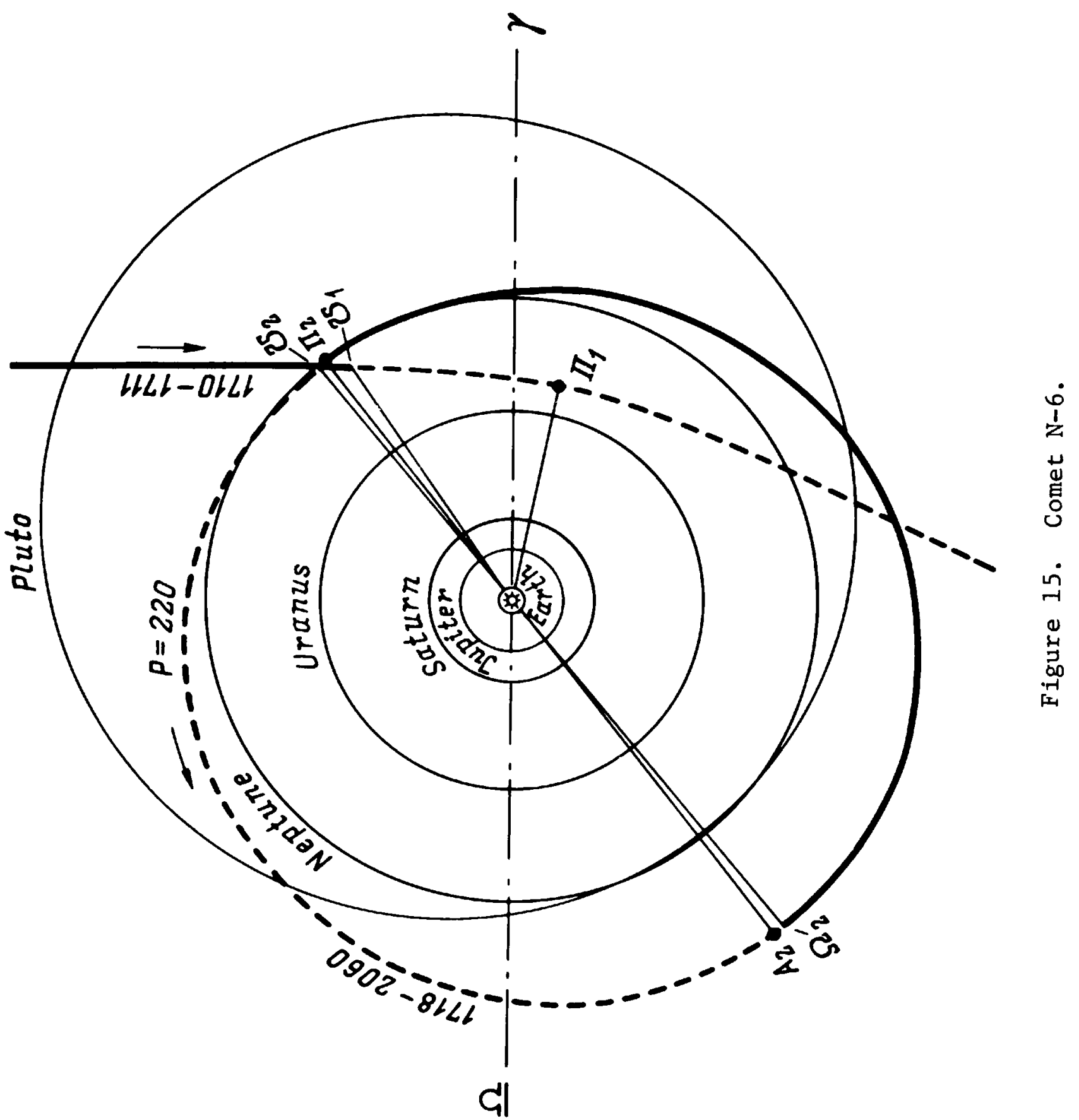




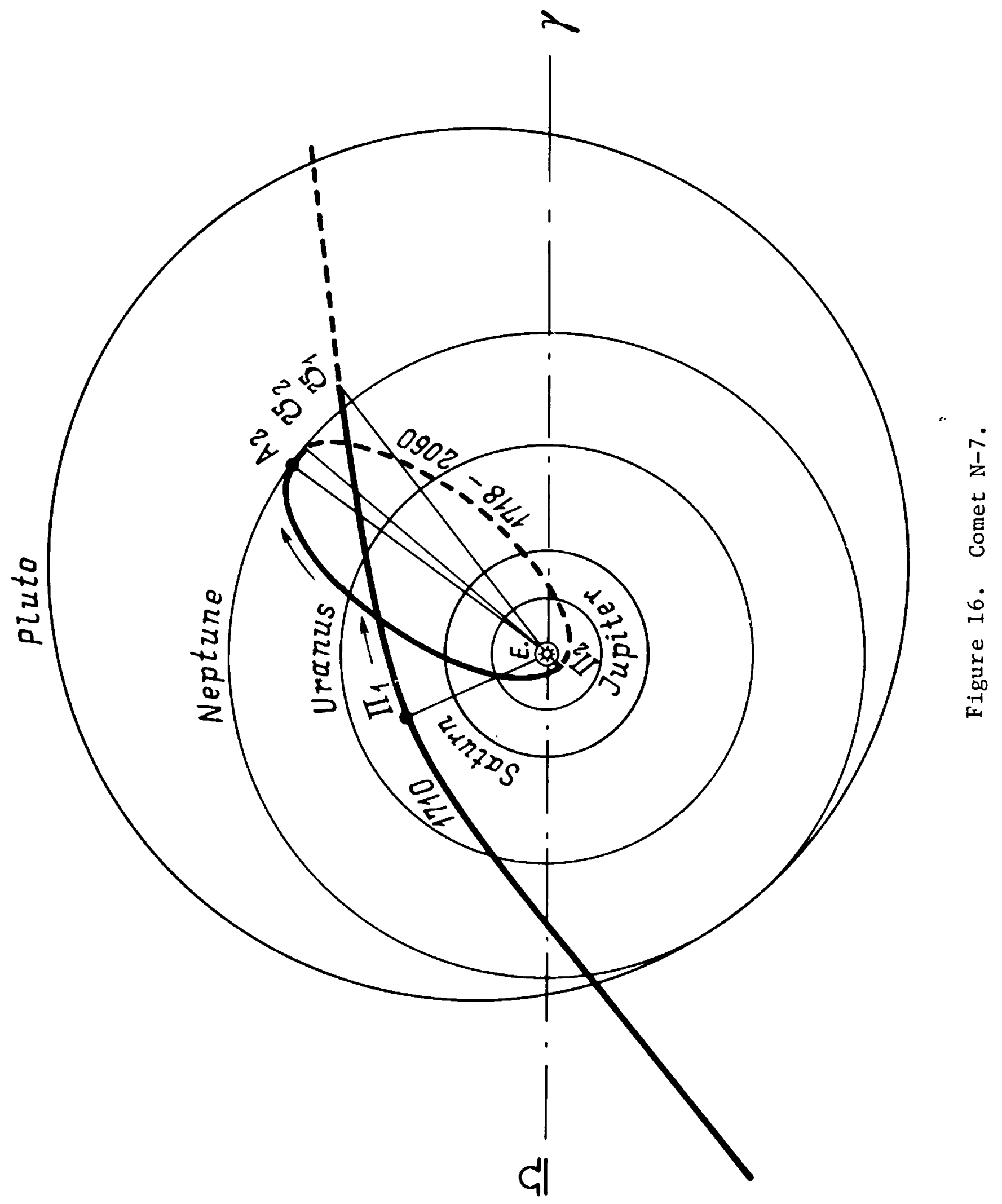




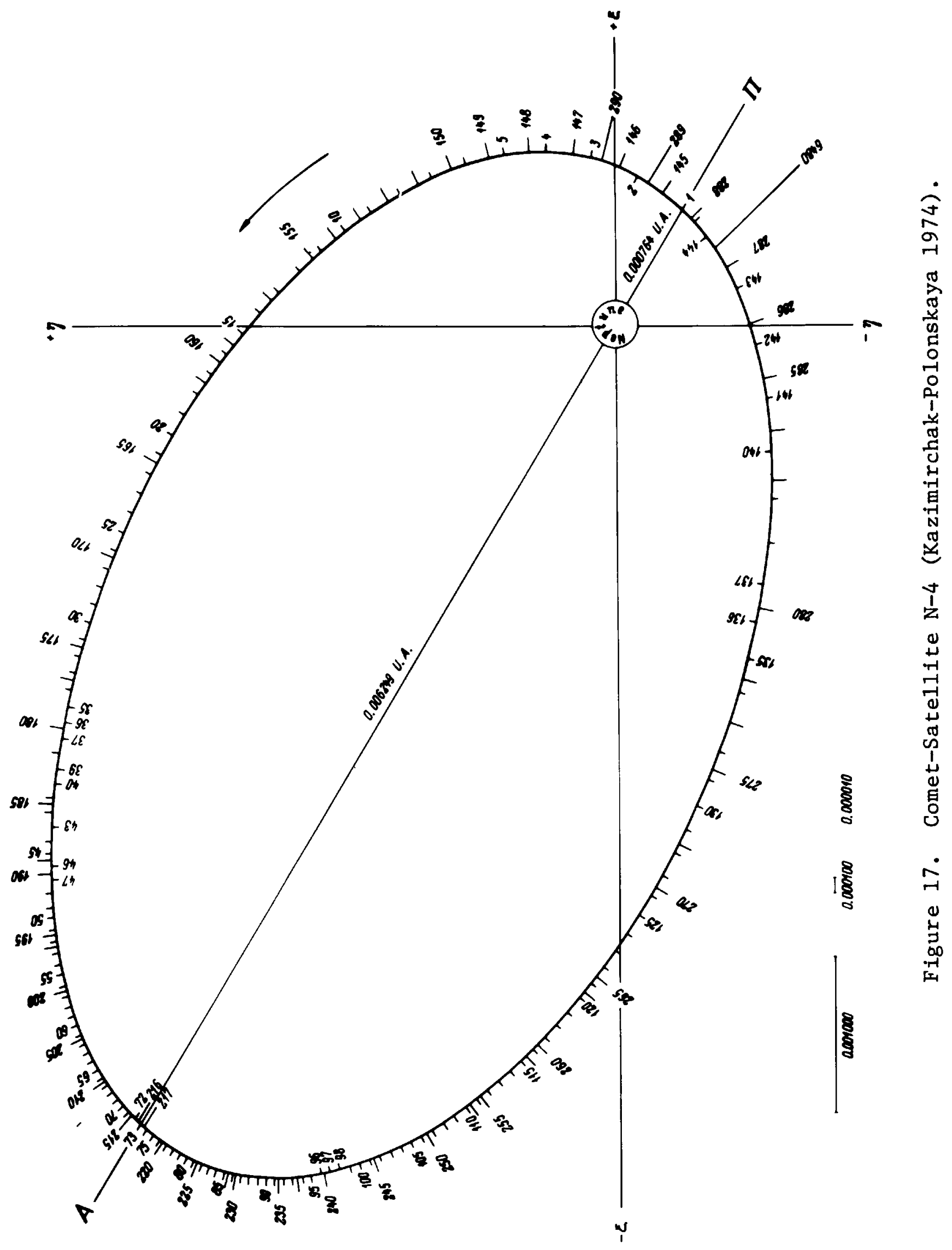


family to another and in exceptional cases can remove them beyond the limits of the solar system; conversely, they can also capture comets from transplutonian and even Erom hyperbolic orbits.

\section{COMETARY ORIGIN}

In a number of papers (Kazimirchak-Polonskaya 1967a, 1967f, 1972c) the author has criticized the classical theory of cometary capture and demonstrated that the various simplifications made -- though perhaps fully justified at the time -- were the cause of contradictions that arose between theoretical deductions (Callandreau 1892; Newton 1893) and the observations.

Using electronic computers and the modern methods of celestial mechanics, we reconsidered the numerical theory of capture and presented the successive stages of cometary orbital evolution, taking into account stellar perturbations and the theory of diffusion. This enabled us to eliminate the discrepancies that formerly existed. Our more recent investigations confirm our view that cometary capture undoubtedly takes place, but it is a very complex process, extending in some cases for perhaps millions of years.

The process begins either with the sun capturing interstellar matter into its own very extended sphere of action, or with the formation, in some way, of a cometary cloud at the periphery of the solar system. The problems of the stability of cometary motion in the outer regions of the solar system and the shape of the cometary cloud have been studied by Chebotarev (1963, 1964, 1966, 1970), Nezhinskij (1972), and Antonov and Latyshev (1972).

Cometary perihelia are thrown into the inner part of the solar system, either as a result of the sun's capiuring an interstellar comet or on account 
of stellar perturbations on comets belonging to the cometary cloud. When such comets penetrate deeply into the sphere of action of one of the outer planets (particularly Jupiter or Neptune) they may be converted -- immediately or in successive stages -- into short-period comets. An interesting example of Jupiter's capture of a fictitious comet on a parabolic orbit has been discussed by Sitarski (1968)

The great majority of the comets in the cometary cloud will diffuse into the inner solar system in the course of $10^{5}$ or $10^{6}$ years and, according to the diffusion laws, they acquire nearly circular orbits of small inclination, with their perihelia concentrated at the distances of the outermost planets. Transplutonian orbits of small inclination and perihelia near the orbit of Neptune may be formed as the result of diffusion (e.g., comet $\mathrm{N}-5$ ) or by Neptune's capture of a comet from interstellar space (e.g., comet $\mathrm{N}-6$ ). At this stage further captures can be made by the giant planets. These captures may develop by a slow evolution or catastrophically. Evolutionary capture consists of a series of successive steps, with capture first by Neptune, then by Uranus, by Saturn, and finally by Jupiter. Catastrophic capture may involve transformation from an interstellar orbit directly into the inner part of the solar system (e.g., comet $\mathrm{N}-7$ ) or the capture by Jupiter of a comet directly from the families of Uranus or Neptune (e.g., P/Kearms-Kwee). This concept of capture permits us to suppose that all comets (whether interstellar or on nearly parabolic orbits, or of long or short period) represent a unified cometary system, the development of which is determined in the spheres of action of the sun and the planets Jupiter to Neptune. Nevertheless, it is desirable that there should be further critical analysis of 
our numerical capture theory, as well as of other hypotheses of cometary origin (e.g., Lagrange 1812; Vsekhsvyatskij 1930, 1933, 1955, 1967. 1969, 1972a, 1972b; Lyttleton 1953; Whipple 1972, Fesenkov 1972; Safronov 1972). 
Table 1

Short-period Comets of Neptune's Family

\begin{tabular}{|lc|c|c|c|c|}
\hline \multicolumn{2}{|c|}{ Name and Designation of Comet } & $q($ A.U. $)$ & $e$ & $p(y r)$ & $i$ \\
\hline$P / N-7$ & 1750 & 1.23 & 0.92 & 61.6 & $136^{\circ}$ \\
$P /$ Pons-Gambart & $1827 \mathrm{II}$ & 0.81 & 0.95 & 63.8 & 136 \\
P/Westphal & $1852 \mathrm{IV}$ & 1.25 & 0.92 & 61.2 & 41 \\
P/Dubyago & $1921 \mathrm{I}$ & 1.12 & 0.93 & 67.0 & 22 \\
\hline
\end{tabular}

Table 2

Characteristic of Orbits of Neptune Satellites: Triton, Nereid and N-4

\begin{tabular}{|c|c|c|c|c|c|c|}
\hline $\begin{array}{c}\text { Satel- } \\
\text { lite }\end{array}$ & $\begin{array}{c}\text { Mean distance } \\
\text { from Neptune } \\
\left(10^{3} \mathrm{~km}\right)\end{array}$ & $\begin{array}{c}\Delta_{\min } \\
\left(10^{3} \mathrm{~km}\right)\end{array}$ & $\begin{array}{c}\Delta_{\max } \\
\left(10^{3} \mathrm{~km}\right)\end{array}$ & $\begin{array}{c}\text { Sidereal period } \\
\text { of revolution }\end{array}$ & $\begin{array}{c}\text { i } \\
\text { of mean } \\
\text { orbit }\end{array}$ & $\begin{array}{c}\text { relative } \\
\text { to ecliptic }\end{array}$ \\
\hline Triton & 354 & 354 & 354 & $5^{d} 21^{\mathrm{hr}} 02^{\min } 39^{\mathrm{sec}}$ & 0.00 & $132^{\circ} .79$ \\
N-4 & 524 & 91 & 957 & 11053112 & 0.73 & 60.87 \\
Nereid & 5570 & 1337 & 9803 & 3590936 & 0.76 & 4.97 \\
\hline
\end{tabular}




\section{References}

Antonov, V.A. and Latyshev, I.N.: 1972, IAU Symposium No. 45, p 341.

Barteneva, 0.N.: 1955, Byul1. Inst. Teor. Astron. 6, 249.

Barteneva, 0.N : 1965, Byuil. Inst. Teor. Astron. 10, 443.

Barteneva, O.N.: 1970, Byull. Inst. Teor. Astron. 12, 252.

Barteneva, 0.N.: 1971, Byul1. Inst. Teor. Astron. 13, 21, 27.

Belous, L.M.: 1960, Byul1. Inst. Teor. Astron. 7, 713.

Belous, L.M.: 1964, Byull. Inst. Teor. Astron. 9, 569.

Belous, L.M.: 1966, Byul1. Inst. Teor. Astron. 10, 543.

Belous, L.M.: 1970, Byull. Inst. Teor. Astron. 12, 257.

Belous, L.M.: 1972, IAU Symposium No. 45, p. 190.

Belous, I.M.: 1974a, Byul1. Inst. Teor. Astron. 13, 501.

Belous, L.M.: 1974b, Byul1. Inst. Teor. Astron. 13, 544.

Belous, L.M.: 1974c, Byull. Inst. Teor. Astron. 13, 548.

Belous, L.M.: 1974d, Byul1. Inst Teor. Astron. 13, 550

Belyaev, N.A.: 1966, Byul1. Inst. Teor. Astron. 10, 696.

Belyaev, N.A.: 1967, Astron. Zh. 44, 461.

Belyaev, N.A.: 1972, IAU Symposium No. 45, p. 90

Belyaev, N.A.: 1973a, Problemy Kosmicheskoj Fiziki 8, 112.

Belyaev, N.A.: 1973b, Trudy Kazanskoj Gorodskoj Astronomicheskoj Observatorii 39,102 .

BeIyaev, N.A. and Khanina, F.B : 1972, IAU Symposium No. 45, p. 16

Belyzev, N.A. and Reznikov, E.A.: 1973, Trudy Kazanskoj Gorodskoj Astronomicheskoj Cbservatorii 39,110 .

Eelyaev, N.A. and Shaporev, S.D.: 1974, Problemy Kosmicheskoj Fiziki 10, 60. 
Belyaev, N.A. and Stal'bovskij, O.I.: 1974, Astronomia i Geodezia (Tomsk)

$$
\text { 4, } 121 \text {. }
$$

Bielicki, M.: 1972, IAU Symposium No. 45, p. 370.

Bokhan, N:A.: 1969, Byull. Inst. Teor. Astron. 11, 677.

Bokhan, N.A.: 1972, IAU Symposium No. 45, p. 86.

Bokhan, N.A. and Chernetenko, Yu.A.: 1974, Astron. Zh. 51, 617.

Brady, J.L.: 1965, Astron. J. 70, 279

Callandreau, 0.: 1892, Ann. Observ. Paris Mém. 20, B.1.

Chebotarev, G.A.: 1963, Astron. Zh. $40,812$.

Chebotarev, G.A.: 1964, Astron. Zh. 41, 983.

Chebotarev, G.A.: 1966, Astron. Zh. 43, 435.

Chebotarev, G.A.: 1970, Byul1. Inst. Teor. Astron. 12, 1 .

Chebotarev, G.A.: 1972, IAU Symposium No. 45, p. 1.

Chebotarev, G.A., Belyaev, N.A. and Eremenko, R.P.: 1970, Byu11. Inst. Teor. Astron. 12, 82

Chebotarev, G.A., Belyaev, N.A. and Eremenko, R.P.: 1972, IAU Symposium No. 45, P. 431 .

Chebotarev, G.A., Belyaev, N.A. and Shmakova, M.Ya.: 1974, Byul1. Inst. Teor. Astron. 13, 477 .

Dinwoodie, C.: 1959, Handb. Brit. Astron. Assoc. for 1960, p. 50.

Dirikis, M.A.: 1953, Astron. Zh. 30, 80 .

Dirikis, M.A.: 1954, Astron. Zh. 31, 461.

Dirikis, M.A.: 1956, Trudy Astron. Sektora Akad. Nauk Latv. SSR 6.

Dubyago, A.D.: 1924, Astron. Abh. Astron. Nachr. 4 , part 8.

Dubyago, A.D.: 1925, Astron. Nachr. 223, 63.

Dubyago, A.D.: 1932a, Astron. Nachr 245, 297.

Dubyago, A.D.: 1932b, Beob. Zirk. Astron. Nachr 14, 36, 43, 54, 65, 72. 
Dubyago, A.D: 1936, Byu11. Astron. Observ.V.P. Engel'gardta No. 6. Dubyago, A.D.:1942, Astron. Zh. 19, 14, 49.

Dubyago, A.D.: 1946, Astron. Tsirk. Akad. Nauk SSSR No. 47.

Dubyago, A.D.: 1948, Astron. Zh. 25, 361.

Dubyago, A.D.: 1950, Trudy Astron. Obs. Kazan No. 31.

Dubyago, A.D.: 1955a, Astron. Tsirk. Akad. Nauk SSSR No. 164

Dubyago, A.D.: 1955b, IAU Circ. Nos. 1533, 1539.

Dubyago, A.D.: 1956a, Byul1. Astron. Observ-V.P. Engel'gardta No. 32.

Dubyago, A.D.: 1956b, Astron. Tsirk, Akad. Nauk SSSR No. 168.

Dubyago, A.D.: 1956c, Astron. Zh. 33, 382 .

Dubyago, A.D. and Lexin, A.: 1923, Astron. Nachr. 219, 153

Evdokimov, Yu.V.: 1972, IAU Symposium No. 45, 173.

Everhart, E.: 1967, Astron. J. 72, 716.

Everhart, E.: 1968, Astron. J. 73, 1039 .

Everhart, E.: 1969, Astron. J. 74, 735 .

Everhart, E.: 1970, Astron. J. 75, 258.

Everhart, E.: 1972a, Astrophys. Lett. 10, 131.

Everhart, E.: 1972b, IAU Symposium No. 45, p. 360.

Everhart, E.: 1973, Astron. J. $\underline{78}, 329$.

Fesenkov, V.G.: 1972, IAU Symposium No. 45, p. 409.

Fokin, A.V.: 1958, Byul1. Inst. Teor. Astron. I, 113.

Galibina, I.V.: 1953, Byu11. Inst. Teor. Astron. 5, 412

Galibina, I.V.: 1958, Byu11. Inst. Teor. Astron. 6 , 630.

Galibina, I.V.: 1963, Byull. Inst. Teor. Astron. 9, 46.

Galibina, I.V.: 1964, Byull. Inst. Teor. Astron. 9, 465.

Galibina, I.V. and Barteneva, O.N.: 1965, ByulI. Inst Teor. Astron. 10, 192

Havnes, O.: 1972, IAU Symposium No. 45, p. 364. 
Herget, P.: 1947, Astron. J 53, 18.

Herrick, S.: 1972, Astrodynamics (London) 2, 79.

Hurnik, H.: 1959, Acta Astron. 9, 207

Hurnik, H.: 1964, Prace Wydž Mat.-Fiz. i Chem. Uniw. A. Mickiewicza w Poznaniu, Ser astron. No. 1.

Kamieński, M.: 1925, Acta Astron. Sér. a 1, 36.

Kamieński, M.: 1926, Publ. Astron. Obs. Warsaw Univ- 2, 1.

Kamieński, M.: 1948a, Bull. Acad. Polon. Sci. Lett. Ser. A 53.

Kamleński, M.: 1948b, Bull. Acad. Polon. Sc1. Lett. Ser. A 103.

Kamfeński, M.: 1951, Bull. Acad. Polon. Sc1. Lett. Ser. A 417.

Kamieński, M.: 1954, Postępy Astron. 2, 137.

Kamieński, M.: 1957, Acta Astron. 7, 159.

Kamieński, M.: 1959, Acta Astron. 9, 53.

Kamieński, M.: 1961, Acta Astron. 11, 33.

Kamieński, M. and Bielicki, M.: 1935, Repr Astron. Obs. Warsaw Univ. 30, 270.

Kamieński, M. and Bielicki, M.: 1936, Repr. Astron. Obs. Warsaw Univ. 32, 1.

Kastel', G.R.: 1965, Byul1. Inst. Teor. Astron. 10, 118.

Kazimirchak-Polonskaya, E.I.: 1950, Tesnje Sblizheniya Komet s Planetami i Planetotsentricheskoe Dw1zhenie Komet (Leningrad Dissertation).

Kazimirchak-Polonskaya, E.I.: 1961a, Trudy Inst. Teor. Astron. ㄱ, 3.

Kazimirchak-Polonskaya, E.I.: 1961b, Trudy Inst. Teor. Astron. ㄱ, 19.

Karimirchak-Polonskaya, E.I.: 1961c, Trudy Inst. Teor. Astron. I, 191.

Kazimirchak-Polonskaya, E.I.: 1962a, Byul1. Inst. Teor. Astron. $8,459$.

Kazimirchak-Polonskaya, E.I.: 1962b, Byull. Inst. Teor. Astron. 8 , 487.

Karimirchak-Polonskaya, E.I.: 1966, Problemy Dvizheniya Malykh Tel Solnechnoj Sistemy (Baku).

Kazimirchak-Polonskaya, E.I.: 1967a, Astron. Zh. 44, 439.

Kazimirchak-Polonskaya, E.I.: 1967b, Trudy Inst. Teor. Astron. 12, 3.

Kazimirchak-Polonskaya, E.I. : 1967c, Trudy Inst. Teor. Astron. 12, 24. 
Kazimirchak-Polonskaya, E.I.: 1967d, Trudy Inst. Teor Astron. 12, 63.

Kazimirchak-Polonskaya, E.I.: 1967e, Trudy Inst Teor Astron. 12, 86.

Kazimirchak-Polonskaya, E.I.: 1967f, Astronomie (Paris) pp. 217, 323, 432

Kazimirchak-Polonskaya, E.I.: 1971, Byull. Inst. Teor Astron. 12, 796.

Kazimirchak-Polonskaya, E.I.: 1972a, IAU Symposium No. 45, 227.

Kazimirchak-Polonskaya, E.I.: 1972b, IAU Symposium No. 45, 95.

Kazimirchak-Polonskaya, E.I.: 1972c, IAU Symposium No. 45, 373.

Kazimirchak-Polonskaya, E.I.: 1973, Sovremennye Problemy Nebesnoj Mekhaniki i Astrodinamiki (Moscow).

Kazimirchak-Polonskaya, E.I.: 1975, IAU Colloquium No. 22.

Kazimirchak-Polonskaya, E.I., Belyaev, N.A., Astapovich, I.S. and Terent'eva, A.K.: 1968, IAU Symposium No. 33, p. 449.

Kazimirchak-Polonskaya, E.I., Belyaev, N.A. and Terent'eva, A.K.: 1972, IAU Symposium No. 45, 462.

Kazimirchak-Polonskaya, E.I. and Terent'eva, A.K.: 1973, Astron. Zh. 50, 576.

Kazimirchak-Polonskaya, E.I. and Belous, L.M.: 1974, Kiev Kometnyj Tsirk. No. 161 .

Kendal1, D.G.: 1961, Proc. Fourth Berkeley Symposium Math. Statistics and Probability (Berkeley-Los Angeles) $\underline{3}, 99,121$.

Kępiñski, F.: 1958, Acta Astron. 8, 193.

Klepczynski, W.J.: 1972, IAU Symposium No. 45, 209.

Kondrat'eva, E.D.: 1972, IAU Symposium No. 45, 200.

Kresák, L.: 1957, Prace Astron. Observ. Skalnatom Plese No. 11.

Kresák, L.: 1972a, IAU Symposium No. 45, p. 503.

Kresák, L.: 1972b, Bul1. Astron. Inst. Czech. 23, 1 .

Kresák, L.: 1973, Bu11. Astron. Inst Czech. 24, 264.

Kulilov, D.K.: 1960, Byul1. Inst. Teor. Astron. I, 770.

Lowrey, B.E.: 1973, Astron. J. 78, 428. 
Lagrange, J.L.: 1812, Sur I'origine des comètes, Mém. VII, 381.

Lyttleton, R.A.: 1948, Monthly Notices Roy. Astron. Soc. 108, No. 6 .

Lyttleton, R.A.: 1953, The Comets and their Origin (Cambridge Univ. Press).

Makover, S.G.: 1955a, Byull. Inst. Teor. Astron. 6, 244.

Makover, S.G.: 1955b, Trudy Inst. Teor Astron. $4,133$.

Marsden, 3.G.: 1963, Astron. J. $\underline{68}, 795$.

Marsden, B.G.: 1964, IAU Circ. No. 1857.

Marsden, B.G.: 1967, Science 155, 1207.

Marsden, B.G.: 1970, Astron. J. 75, 206.

Marsden, B.G. and Aksnes, K.: 1967, Astron. J. 72, 952.

Marsden, B.G. and Schubart, J.: 1965, IAU Circ. No. 1911.

Merton, G.: 1927, Mem. Roy. Astron. Soc. 64, 47.

Merzlyakova, M.A.: 1958, Byull. Inst. Teor. Astron. I, 120.

Merzlyakova, M.A.: 1974, Byul1. Inst. Teor. Astron. 13, 554.

Mikhajlov, A.A.: 1924, Astron. Zh. 1,56 .

Neujmin, G.N.: 1948, Izv- Glavnoj Astron. Obs. Pulkovo 17, No. 6.

Newton, H.A.: 1878, Amer. J. Sci. Arts (New Haven, Conn.) Ser. 3, 16 (116), 165.

Newton, H.A.: 1893, Mem. Nat. Acad. Sci. Washington 6, 7.

Nezhinskij, E.M.: 1972, IAU Symposium No. 45, p. 335.

Oort, J.H.: 1950, Bul1. Astron. Inst. Netherl. 11, 91.

Oppenheim, S.: 1924, Probleme der Astronomie, Festschrift für H. v. Seeliger (Berlin).

Poor, C.L.: 1894, Astron. J. 13, 123, 177.

Rasmusen, H.Q.: 1935, Publ. Medd. Kbenh. Obs. No. 106.

Safronov: V.S.: 1972, IAU Symposium No. 45, p. 329.

Sakk, V V. and Kulikov, D.K.: 1951, Byull. Inst. Teor. Astron. 4, 431.

Schubart, J. and Stumpff, P.: 1960́, Veröffent1. Astron. Rechen-Inst. No. 18. 
Sekanina, Z.: 1966, Acta Univ. Carol. Math.-Phys. 2, 3.

Shmakova, M.Ya.: 1953, Byul1. Inst. Teor Astron. 5 , 420.

Shmakova, M.Ya.: 1972, IAU Symposium No. 45, p. 203.

Shtejns, K.A.: 1960, Ucz: Zap. Latv. Gos. Univ. 38, 69.

Shtejns, K.A.: 1961, Astron. Zh. 38, 107, 304.

Shtejns, K.A.: 1962, Astron. Zh. 39, 915.

Shtejns, K.A.: 1964, Ucz. Zap. Latv. Gos. Univ- 68, 39.

Shtejns, K.A.: 1972, IAU Symposium No. 45, p. 347

Shtejns, K.A. and Kronkalne, S.: 1964, Acta Astron. 14, 311.

Shtejns, K.A. and Kronkalne, S.: 1968, Izv. Akad. Nauk Latv- SSR 9, 59.

Shtejns, K.A. and Riekstyn'sh, E.I.: 1960, Astron. Zh. 37, 1061.

Shtejns, K.A. and Sture, S.J.: 1962, Astron. Zh. 39, 506.

Sitarski, G.: 1968, Acta Astron. 18, 171.

Sochilina, A.S.: 1958, Byul1. Inst. Teor. Astron. $\underline{6}, 671$.

Stumpff, P.: 1972, IAU Symposium No. 45, p. 156.

Svedstrup, A.: 1883, Astron. Nachr. 107, 113.

Vaghi, S.: 1973a, Astron. Astrophys. 24, 107.

Vaghi, S.: 1973b, Astron. Astrophys. 29, 85.

van Woerkom, A.J.: 1948, BuI1. Astron. Inst. Nether1. 10, 445.

Vsekhsvyatskij, S.K.: 1930, Monthly Notices Roy. Astron. Soc. 90, 706.

Vsekhsvyatskij, S.K.: 1933, Astron. Zh. 10, 18.

Vsekhsvyatskij, S.K.: 1955, Astron. Zh. 32, 432 .

Vsekhsvyatskij, S.K.: 1967, Priroda i Proiskhozhdenie Komet i Meteornogo Veshchestva (Moscow).

Vsekhsvyatskij, S.K.: 1969, Problemy Sovremennoj Kosmogonii (Moscow), p. 240 Vsekhsvyatskij, S.K.: 1972a, IAU Symposium No. 45, p. 356. 
Vsekhsvyatskij, S.K.: 1972b, IAU Symposium No. 45, p- 413.

Whipple, F.I.: 1950, Astrophys J 111, 375.

Whipple, F.L : 1951, Astrophys. J. 113, 464.

Whipple, F.L.: 1962, Astron. J. 67, 1.

Whipple, F.L.: 1972, IAU Symposium No. 45, p. 401.

Witkowski, J.M.: 1953, Bul1. Soc. Amis. Sci. Lett. Poznań Sér. B 12, 205.

Witkowski, J.M.: 1965, Acta Astron. 15, 233.

Witkowski, J.M.: 1968, Observatory 88, 27.

Witkowski, J.M.: 1971, Astron. Vestnik (Moscow) 5, 82.

Witkowski, J.M.: 1972, IAU Symposium No. 45, p. 419. 